
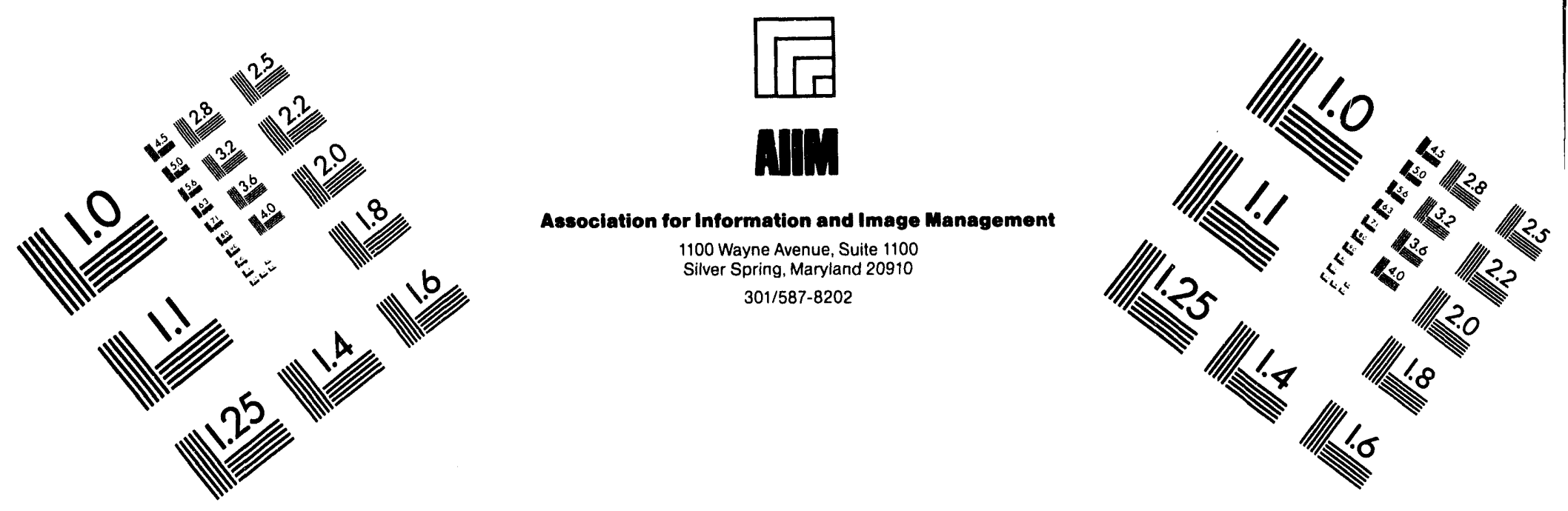

Centimeter

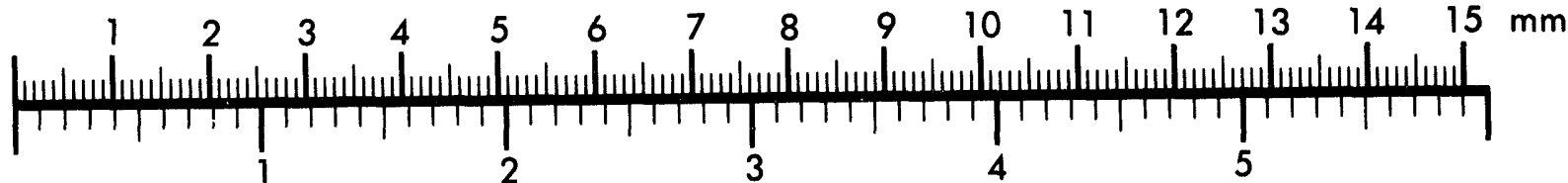
Inches
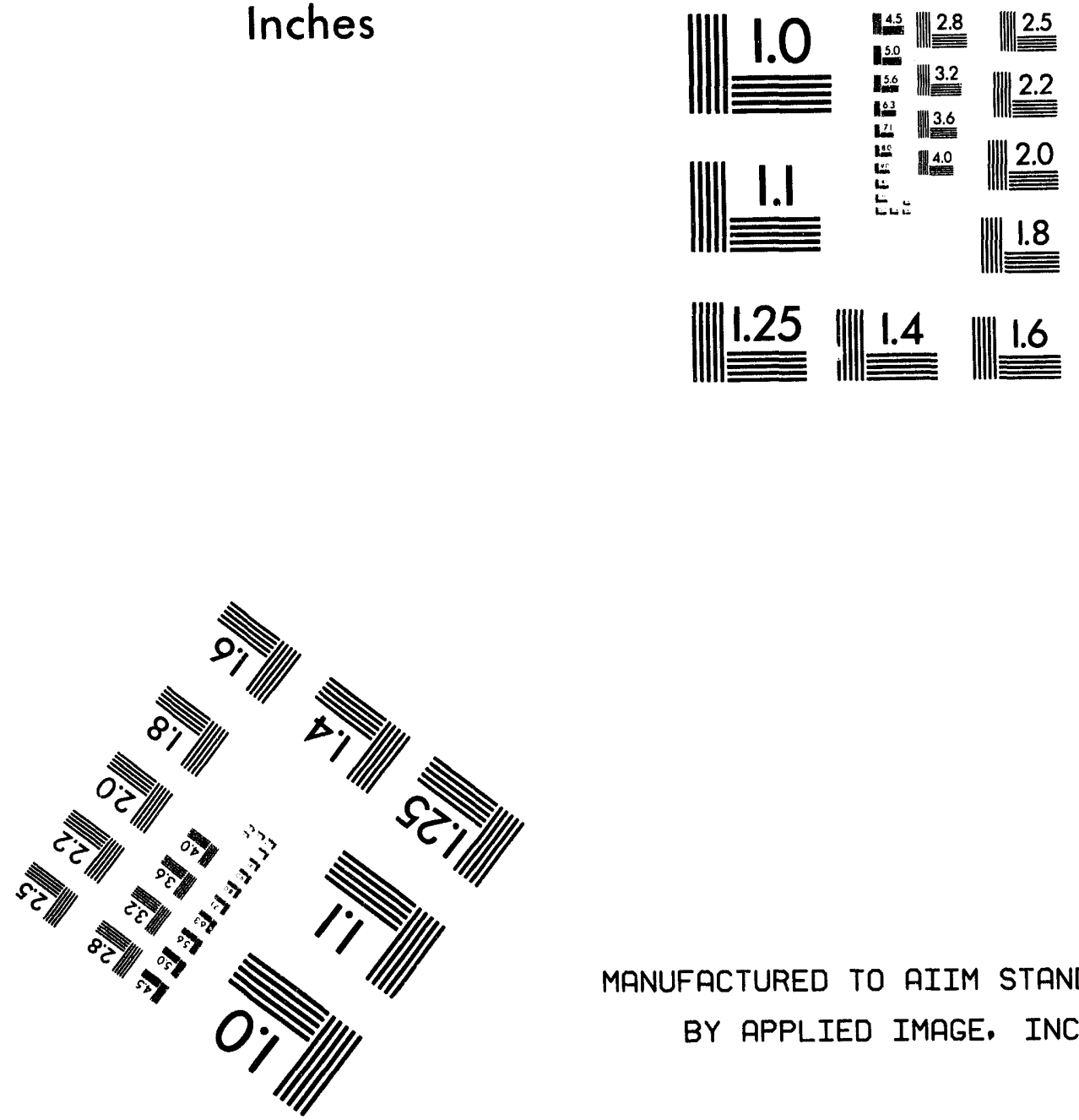

MANUFACTURED TO AIIM STANDARDS

BY APPLIED IMAGE. INC.

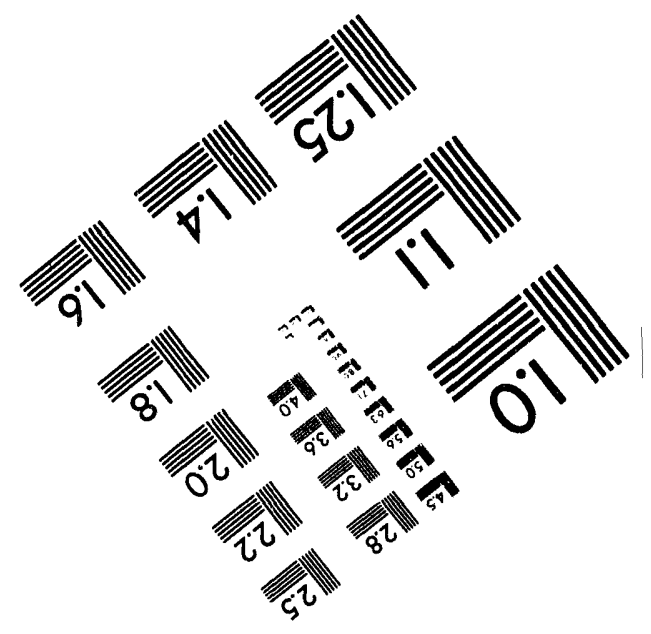



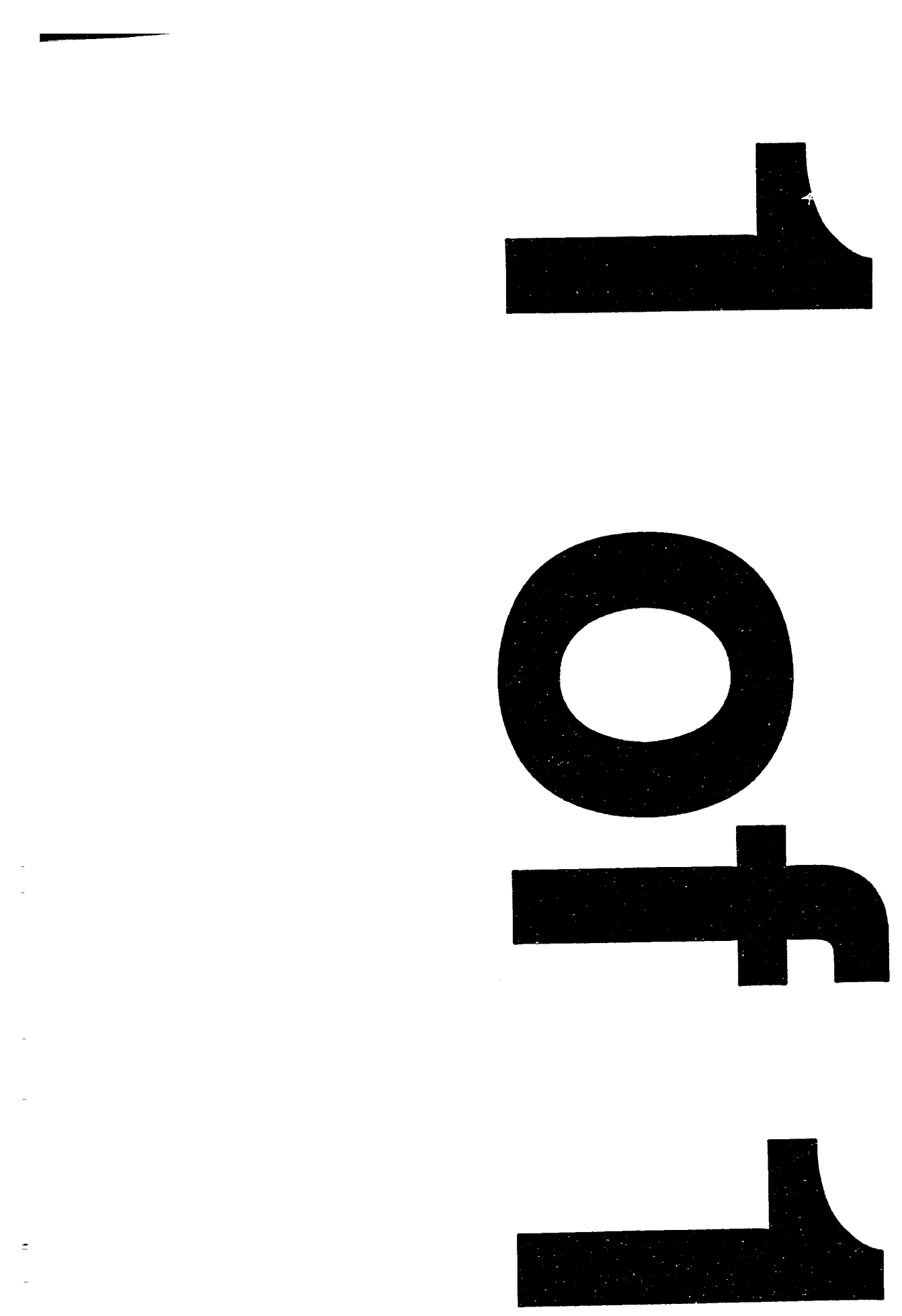
2

DISTRIBUTION SHEET

\begin{tabular}{|c|c|c|c|c|c|}
\hline \multirow{2}{*}{$\begin{array}{l}\text { To } \\
\text { Distribution }\end{array}$} & \multirow{2}{*}{\multicolumn{3}{|c|}{$\begin{array}{l}\text { From } \\
\text { Criticality \& Radiological } \\
\text { Analyses }\end{array}$}} & \multicolumn{2}{|l|}{ Page 1 of 1} \\
\hline & & & & \multicolumn{2}{|c|}{ Date July 25, 1994} \\
\hline \multicolumn{4}{|c|}{ Project Title/Work Order } & \multicolumn{2}{|c|}{ EDT No. 161566} \\
\hline \multicolumn{4}{|c|}{$\begin{array}{l}\text { User's Guide to The FFTF Plant Operational Data Management } \\
\text { System (B1039) }\end{array}$} & ECN No. $N / A$ & \\
\hline Name & MSIN & $\begin{array}{l}\text { Text } \\
\text { With All } \\
\text { Attach. }\end{array}$ & Text Only & $\begin{array}{l}\text { Attach./ } \\
\text { Appendix } \\
\text { Only }\end{array}$ & $\begin{array}{l}\text { EDT/ECN } \\
\text { Only }\end{array}$ \\
\hline
\end{tabular}

D. M. Ahrens RECEIVED $H 4-64 \quad x$

J. W. Daughtry SEP 191994

N2-32

$x$

S. F. Kessler

OSTI

N2-32

$x$

J. V. Nelson, Jr.

H4-64 $X$

R. F. Richard

H4-64 $X$

C\&RA File

H4-64 $x$

Technical Reference Center

N2-12 $x$

Central files (Orig. +2)

L8-04 $x$

IRA (2)

H4-17 $X$ 


\begin{tabular}{|c|c|c|}
\hline AUG 151994 & ENGINEERING DATA TRANSMITTAL & 1. EDT $1615 \frac{1}{66}$ \\
\hline
\end{tabular}

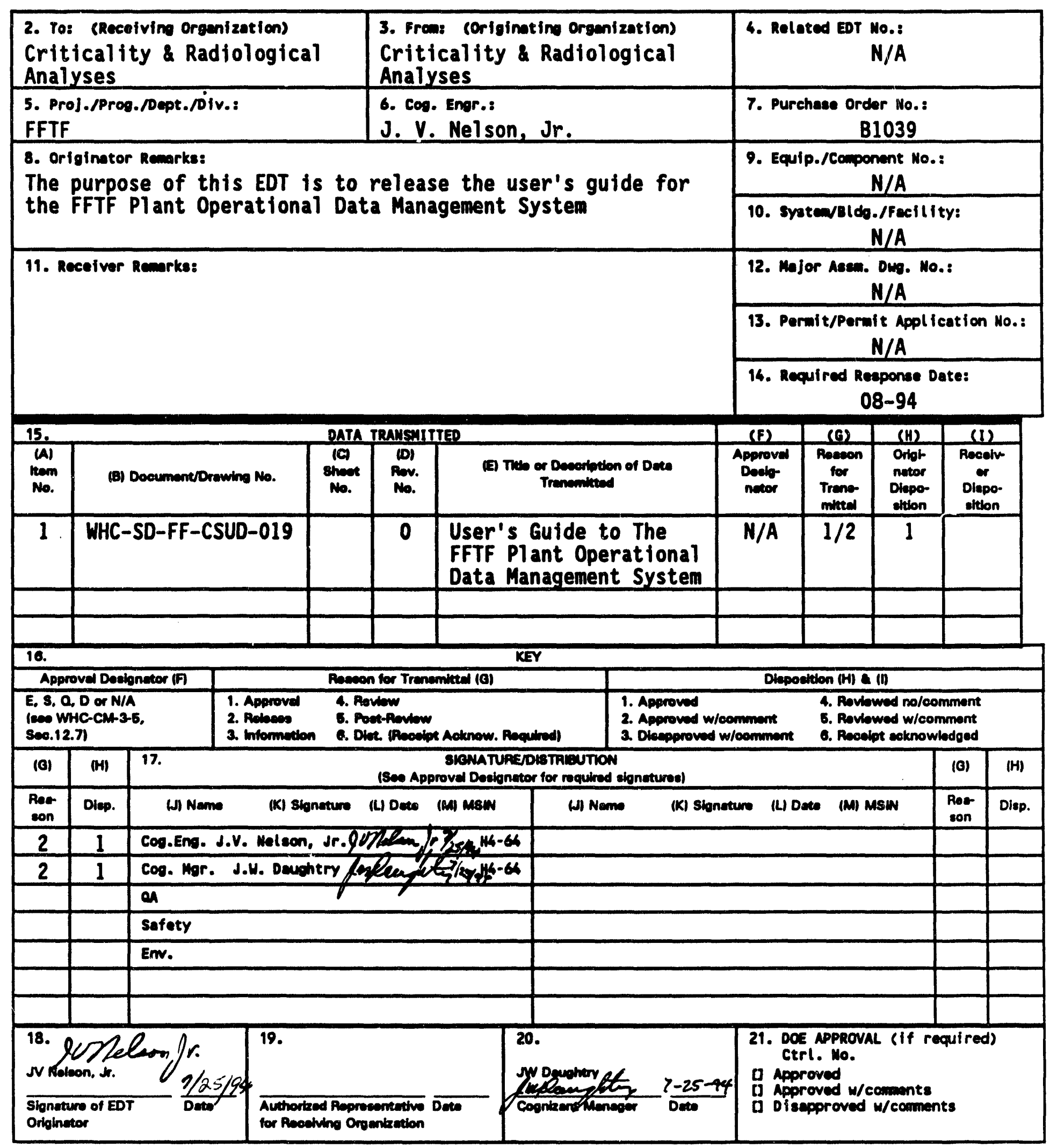

BD-7400-172-2 (04/94) GEF097 


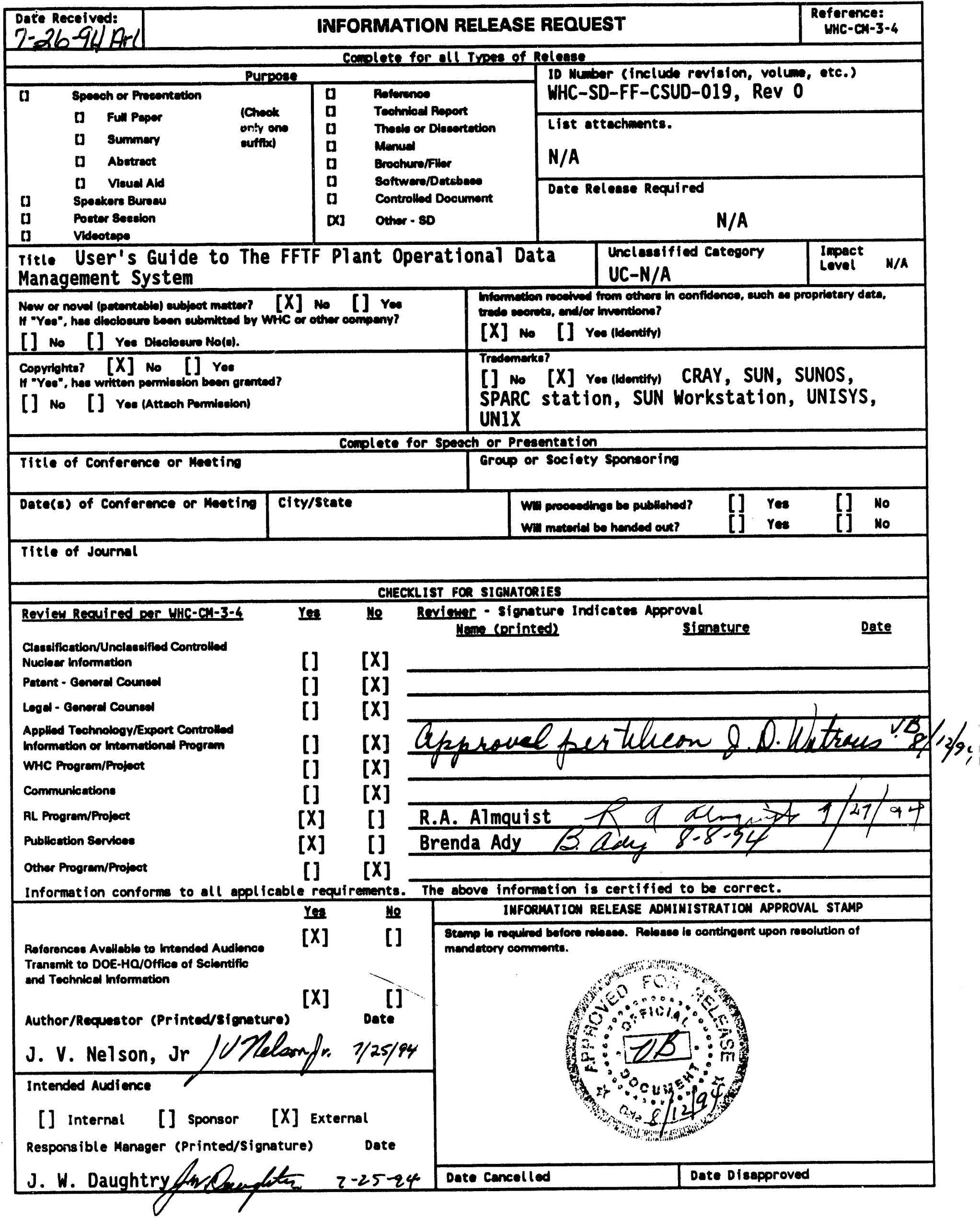




\section{Title}

User's Guide to The FFTF Plant Operational Data Management System

5. Key Words

FFTF, Data Management, Nuclear Reactor, Operational Datą

\section{APPROVED FOR PUBLIC RELEASE}

7. Abstract

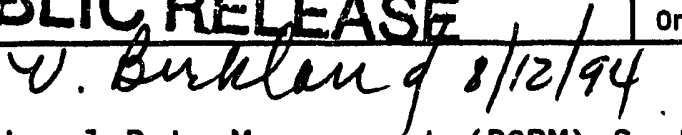

3. Number

WHC-SD-FF-CSUD-019 4. Rev No.

The FFTF Plant Operational Data Management (PODM) System was designed to store manage and retrieve operational data recorded by computer-based data acquisition systems in the FFTF.

This document describes the PODM system and includes detailed instructions for using the computer software available to retrieve and process the stored FFTF data.

8. PURPOSE NND USE OF DOCUMENT - This document was prepared for use within the Y.S. Department of Energy and its Eantractors. It is to be used only to perform, direct, or integrate work under U.S. Department of Eneras contracts. This documeht is not approved for public releasa unth reviewed.

PATENT STATUS - This document copy, since jh is transmitted in advance of paten clearance, is made available in confidence solely for use in performance of work under contracts with the U.S. Department of Energy. This document is not to be puplished nor its content otherwise disseminated or used for purposes other than specified/above before patent aduroval for such release or use has been secured, upon request, from the Patent Counsel, U.S. Department of Energy Field Office, Richland, Wh.

DISCLAIMER - This report was prepared as an account of work sponsored by an agency of the United States Government. Neither the United States Government nor any agency thereof, nor any of their employees, nor any of their contractors, subcontractors or their employees, makes any warranty, express or implied, or assumes any legal liability or responsibility for the accuracy, completeness, or any third party's use or the results of such use of any information, apparatus, product, or process disclosed, or represents that its use would not intringe privately owned rights. Reference herein to any specific commercial product, process, or service by trade name, trademark, manufecturer, or otherwise, does not necessarily constitute or imply its endorsement, recommendation, or favoring by the United states Government or any agency thereof or its contractors or subcontractors. The views and opinions of authors expressed herein do not necessarily state or reflect those of the United States Government or any agency thereof.

10.

RELEASE STAMP

6. Author

Name: J. V. Neison, Ir.

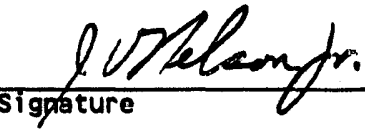

Organization/Charge Code 8D150/B1039

OFFICIAL RELEASE BY WHIC

DATE AUG 151994

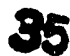

Station 21 


\title{
USER'S GUIDE TO THE FFTF PLANT OPERATIONAL DATA MANAGEMENT SYSTEM
}

\author{
J. V. Nelson
}

July 20, 1994

\section{TABLE OF CONTENTS}

Page

1.0 SUMMARY ...................... 1

2.0 INTRODUCTION .................... 2

2.1 Purpose .................. 2

2.2 Scope ................... 2

2.3 Environment ................. 3

2.4 Background ................. 3

2.5 Related Documentation................ 4

3.0 FLOW OF INFORMATION INTO THE DATA BASE . . . . . . . . . 4

4.0 DATA BASE ORGANIZATION AND CONTENT . . . . . . . . . . 6

5.0 PROGRAMS PROVIDING DIRECT ACCESS TO THE DATA BASE . . . . . . 8

5.1 Data File Assignment Routine, REQFL . . . . . . . . . 8

5.2 The Data Review Program, CDREV . . . . . . . . . . . 9

5.3 Program to Generate User Files, GULF ............ 10

5.4 Program to Time Average Sensor Data, CGULF . . . . . . . . 11

5.5 Programs to Summarize Pump Motor Operations, PUMPS and PMPRPT . 11

6.0 PROGRAMS ACCESSING GULF AND CGULF GENERATED FILES . . . . . . . . . 12

6.1 Program to Average Sensor Data, SENAV . . . . . . . . . 12

6.2 Program to Generate Plot Files, GPD . . . . . . . . . 12

6.3 Programs to Merge GULF-Format Files, MERGF ......... 13

7.0 SUBROUTINE LIBRARY FOR DATA RETRIEVAL AND PROCESSING . . . . . . 13

8.0 REFERENCES . . . . . . . . . . . . . . 15

\section{APPENDICES}

A Content of Sensor Records in Operational Data Base . . . . . . . 16

B Content of FFTF Operational Data Base . . . . . . . . . . . . 19

C Instructions for Using Programs in the PODM Library . . . . . . . . 22

D Instructions for Using the PODM Subroutine Library, PODMLIB . . . . 48

E Sample REQFL/CDREV Run in the Batch Mode ...........663

F IVHM Parameters Stored in the Data Base . . . . . . . . . 65 


\section{LIST OF FIGURES}

3-1 Flow of FFTF Operational Data Into Data Base . . . . . . . . 5

\section{LIST OF TABLES}

3-1 Breakdown of Plant Sensors Into Groups . . . . . . . . . . 7

7-1 Data Retrieval Subroutines in PODMLIB . . . . . . . . . . . . 13

7-2 0ther Subroutines and Functions in PODMLIB . . . . . . . . 14

A-1 Engineering Units Codes . . . . . . . . . . . . . 17

A-2 DDH\&DS Status Bits . . . . . . . . . . . . . . 18

B-1 Sample LSTMFD Report . . . . . . . . . . . . . . . . . . 20

B-2 LSTMFD Input Cards ................ 21

C-1 Content of GULF Records Written to a FORTRAN Binary file (Option 0 ) . 31

C-2 Content of GULF Records Written to a FORTRAN Formatted File Using Option $1 \ldots \ldots 32$

C-3 Content of GULF Records Written to a Packed ASCII File Using Option $2 \ldots \ldots \ldots \ldots$

C-4 Format of File pmphis . . . . . . . . . . . . . . .41

C-5 Typical PUMPS Input ................... . . 42

C-6 Typical PMPRPT Runstream . . . . . . . . . . . . . . . . . . .42

D-1 Internal PODM Representation of a Date . . . . . . . . . .62

D-2 Content of Fourth Word of Data Record Returned by GETMSO . . . . . 62

E-1 Sample CDREV Runstream . . . . . . . . . . . . . 64 


\section{USER'S GUIDE TO THE FFTF PLANT OPERATIONAL \\ DATA MANAGEMENT SYSTEM}

\subsection{SUMMARY}

The FFTF Plant Operational Data Management (PODM) System provides capabilities for storing, managing and retrieving data recorded by FFTF plant computers [the Plant Data System (PDS), in particular]. The PODM system is currently implemented on SUN" Workstations ${ }^{(R)}$. This guide contains a description of the PODM System, and instructions for using programs available for retrieving and processing FFTF data stored in the data base.

Section 2.0 provides a brief overview and the background of the system. The organization and content of the data base are described in more detail in Sections 3.0 and 4.0. Available computer programs are described in sections 5.0 and 6.0 while subroutines that can be called by a user's FORTRAN program are described in section 7.0 .

TM SUN is a trademark of Sun Microsystems, Inc.

(R) SUN workstation is a registered trademark of Sun Microsystems, Inc. 


\subsection{INTRODUCTION}

A number of computers in the FFTF plant monitor and record data indicating the performance, environment and status of FFTF systems, components and tests. Data tapes recorded by some of these computers have been processed and stored for retrieval by PODM System software. In general, the PODM system was designed to provide long-term retention of FFTF operational records in computer retrievable form for use by operations, operations support, engineering, safety, and experimenter organizations. Specific functional requirements that the system was designed to satisfy can be found in References 1 and 2. Preliminary scoping and planning work was documented in References 3 and 4 .

\subsection{Purpose}

The purpose of this guide is to briefly describe the PODM system and provide detailed instructions for using software available for retrieving, processing and displaying information in the data base.

\subsection{Scope}

Data recorded by three plant computers have been loaded into the data base in the past. Two computers are part of the Digital Data Handling and Display System (DDH\&DS). These are the Plant Data System (PDS) and the Experimenters Data System (EDS). The PDS records facility data such as reactor power, core temperatures and temperatures, flowrates and pressures in the heat transport system. The EDS records experimenters' data from instrumented test assemblies, plus key facility data as a backup to the PDS. The third data source is the In-Vessel Handling Machine (IVHM) computer that records assembly insertion and withdrawal forces during refueling operations. Recently though, only data recorded by the PDS have been processed into the data base.

SPARCstation is a trademark of SPARC International, Inc. SUNOS is a trademark of SUN Microsystems, Inc. 


\subsection{Environment}

The PODM System is currently : plemented on SUN SPARCstation 2 computers cesl and ces3. These workstations operate under SUNOS 4 4.1.1. Almost all coding is in FORTRAN 77. One subroutine in one program was coded in $C$. The FORTRAN code was compiled using f77.1.3.1, and the $C$ code was compiled using the $C$ compiler distributed with SUNOS 4.1.1.

Executable code and UNIX(R) shell scripts are maintained on SUN disk space. Data base files are maintained on the Common File System (CFS), but must be transferred to SUN temporary disk space for processing. This transfer is handled automatically by the PODM System.

\subsection{Background}

The PODM System was first implemented on a UNISYS" 1100 computer (Ref. 5). A11 data recorded by the PDS from July 27, 1979 to September 24, 1988 were stored using the system implemented on the UNISYS computer. The EDS began recording data routinely on July 10, 1980. Data recorded by the EDS from then to September 2, 1988 were processed using the UNISYS.

In September 1988, the PODM was migrated to the first Hanford CRAY(R) computer. PDS data recorded from September 16, 1988 to August 12, 1993 were processed using the CRAY-based PODM system. EDS data recorded from September 2, 1988 to December 23, 1989 were processed using the CRAY-based system. EDS data recorded after that time were not processed.

Data recorded by the IVHM computer from October 18, 1988 to December 25, 1989 were processed into the FFTF data base.

In August 1993, the PODM System was migrated from the second Hanford CRAY computer to the SUN workstations, where the system currently resides.

(R) UNIX is a registered trademark of UNIX System Laboratories, Inc.
CRAY is a registered of Cray Research, Inc.
UNISYS is a trademark of UNISYS Corp.


The FFTF data processed by the UNISYS computer were written to magnetic tape. Data processed on the two CRAY computers and the SUN workstations were written to disk files, which were eventually transferred to CFS for permanent storage. Data tapes created by the UNISYS cannot be read by PODM software on the SUN workstations. However, data files created by the CRAY computers can be read using the SUNs even though the file formats are different. The differences are completely transparent to the user.

To access FFTF data processed before the PODM System was operational on the Hanford CRAY (September 1988), the original copies of the data tapes must be obtained from the records center and processed on the SUN system.

\subsection{Related Documentation}

References 2 - 5, cited earlier, provide more background on the PODM System. Reference 1 described the programs used to process data tapes from FFTF computers and maintain the data base. This document also provides source code listings, version numbers and release dates for all PODM programs.

\subsection{FLOW OF INFORMATION INTO THE DATA BASE}

The steps involved in transferring operational data on magnetic tape from FFTF plant computers to the data base are outlined in Figure 3-1. Tapes containing data to be entered into the data base are first duplicated at the FFTF site. The originals are stored at the 400 Area and the copies are sent via messenger service to the central computer facility in the Federal Building. There, they are read on the Large Scale Information System (LSIS) and copied to disk. The disk files are then transferred to a SUN workstation (cesl or ces3) for processing.

Data from the PDS and EDS are translated and partitioned into logical sensor groups during this processing. Data in each group are then used to update separate disk files. In Figure 3-1, two PDS and two EDS groups are shown only for illustrative purposes. In fact, PDS data are divided into four groups and there was one EDS group per experimenter organization having instrumented 
WHC-SD-FF-CSUD-019

Revision 0

Page 5

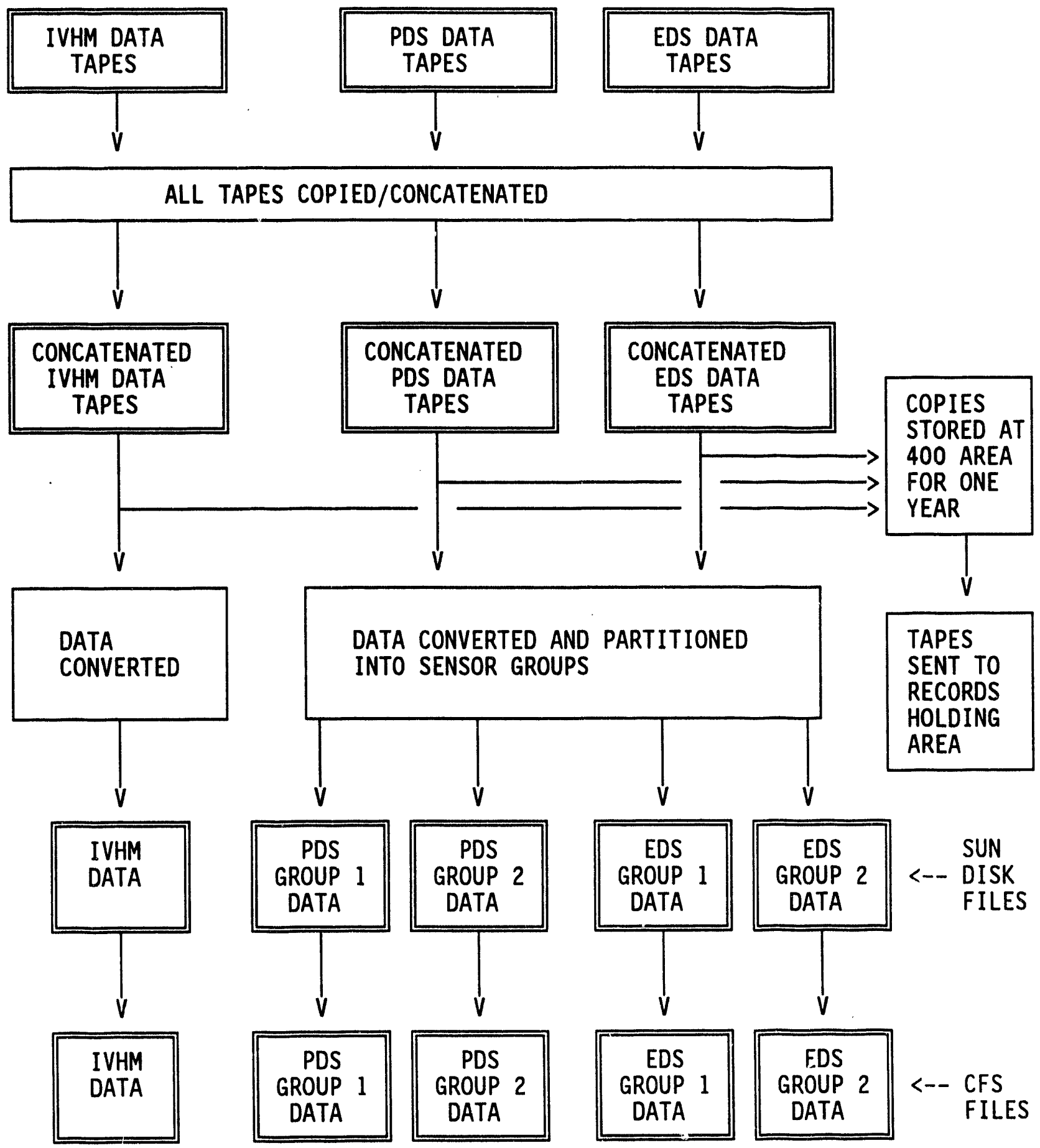

Figure 3-1. Flow of FFTF Operational Data into Data Base 
WHC-SD-FF-CSUD-019 ,

Revision 0

Page 6

tests in the reactor, plus one group for facility data backed up on the EDS. The general breakdown of PDS facility data into the four groups is summaried in Table 3-1.

Data records from the IVHM computer were reformatted during duplication to be in the same format as PDS and EDS tapes. IVHM data were then processed like PDS and EDS data except that IVHM data were not divided into different groups.

\subsection{DATA BASE ORGANIZATION AND CONTENT}

As indicated above, sensor records are segregated into groups as they are processed into the data base. Groups 1, 2, 3, and 5 contain the PDS data summarized in Table 3-1. Group 11 contains key facility data recordcd by the EDS as backup. Group 20 contains all available data recorded by the IVIM computer.

Each variable record in the data base includes a sensor identifier, a value in engineering units, the date and time recorded and a number of status flags. (A detailed description of the records is given in Appendix A). Complete tabulation of variables recorded by the PDS and EDS is not included in this report because of the large number of sensors involved. Also, there can be changes from cycle to cycle. A current list of sensors recorded by the PDS is available. The available IVHM parameters are listed in Appendix G. 


\section{Table 3-1}

Breakdown of Plant Sensors Into Groups

Group

1

5

\section{Content}

Subassembly powers

Subassembly temperature

Subassembly flow rates

Total power

Reactivity

Flux Deviations

Inlet and outlet temperatures

Flow fraction

Other temperatures

- Primary and secondary loops

- IHX and DHX

- Instrument tree

- Head

- Vessel nozzle

Data on primary and secondary 10op systems

- Flow

- Pump speed

- Sodium level

- Pressure

DHX valve positions

Blower speed and damper positions

Control rod positions

LLFM and EVFM count rates

Flux source rate

Radiation and particle monitors

Calibration data

PPS channels

All System 61 sensors

All System 81 sensors 


\subsection{PROGRAMS PROVIDING DIRECT ALCESS TO THE DATA BASE}

Sections 5.1 through 6.3 contain brief descriptions of programs that are available for retrieving, displaying and analyzing FFTF operational data. Further details and instructions on these programs can be found in Appendix $C$. Section 5.1 through 5.5 are devoted to programs that obtain information directly from the data base while Sections 6.0 through 6.3 deal with programs to process operational data that have been previously extracted from the data base and stored on user files.

\subsection{Data File Assignment Routine, REQFL}

Because of the volume of data produced by multiple FFTF plant computers and the division of data into logical sensor groupings, the operational data base consists of a large number of files. To eliminate the necessity of having to determine which file(s) contain information of particular interest, the REQFL program that automatically selects and assigns required data files was written. A second function of REQFL is to provide data security by controlling access to the data base. Before REQFL assigns any files, a master password must be supplied by the user. This password allows access to all facility data. The security system also has the capability of providing additional security for experimenter-owned data from instrumented test assemblies.

After requesting and checking a user's password entry, REQFL reads the range of dates and times over which data are requested. Finally, REQFL reads identifiers for the required sensors, or the numbers of the groups into which these sensors have been $\mathrm{placed.}$ Using this information, the program determines which files contain the required data and initiates instructions for requested files to be transferred from CFS to temporary on-line disk files, if necessary. REQFL also writes a communication file expected by most data retrieval routines.

Even though assignment of data files necessary to complete a requested report is automatic, the user still needs to have an idea of how many files are 
necessary. No more than 12 data files can be assigned for any data group in a single run. Methods for determining in advance how many input files must be read to complete a desired report are presented in Appendix B: It may require 10 minutes to stage and transfer each file from CFS.

Another feature of the REQFL program allows the user to specify that only the latest file in each specified group is to be assigned. This option is useful if a user wants to interactively look at only the most recent information in the data base without knowing in advance the time period of data included on the files.

Detailed input instruction of REQFL are given in Appendix C.1.

\subsection{The Data Review Program, CDREV}

The CDREV program is designed to produce correlated data reports in either the batch or interactive mode. CDREV is used in conjunction with the REQFL preprocessor that assigns files containing records for the sensors and the time intervals requested. Input instructions for CDREV are given in Appendix C. 2 with examples. A complete batch runstream is listed and described in Appendix $E$ and an annotated printout from a typical interactive session is given in Appendix $F$. Some of the general features and limitations of the CDREV program are discussed in the following paragraphs.

An example of a report produced by CDREV is shown in Appendix F. A single report can contain information on up to 200 sensors. The number of columns of sensor data on a single page is specified by the user, but cannot exceed ten. The number of data 1 ines on each page is 45 . If a report is to list data for more sensors than can be put on one page, consecutive pages will be used to include all sensors at each set of 45 time periods. The time interval between each 1 ine in the report is also specified by the user and can be any value between $0.1 \mathrm{sec}$. and 24 hours. If more than one value is recorded for a particular sensor in a single time interval, the first recording encountered is printed. 
The CDREV program requires less than 200K bytes of memory to execute. Running times are job dependent and can range from a few seconds to over several minutes. Computer time is a function of the number of files required, length of the time period over which data re retrieved and the specified retrieval frequency.

The status of sensor values printed by CDREV is indicated by a single character immediately following the value printed. Status flags that could appear include:

$H$ - The value exceeds the high alarm limit.

$L$ - The value is below the low alarm limit.

* - The value is outside the valid sensor range.

$N$ - The scan rate for this sensor has been changed.

When successive recordings of a sensor are invalid, the DDH\&DS also labels all following values as being invalid until a reactor operator resets the invalid al arm.

\subsection{Program to Generate User Files, GULF}

The GULF program was designed to create data files containing user-specified subsets of the data base. This program is similar to CDREV in that a time period and a set of sensor identifiers $(\leq 800)$ are specified via input. Also like CDREV, a time increment to allow regulation of the frequency of data output records is specified. Each sensor record written to the output file by GULF consists of:

- The data and time

- Sensor identifier

- Sensor value in engineering units

- Engineering units code

- DDH\&DS status word

where the units codes and status bits are defined in Appendix A.

Three options for the format of the output file are available. The first is a standard FORTRAN binary file with each logical record containing the data for one sensor at one time interval. The other two options are FORTRAN formatted 
WHC-SD-FF-CSUD-019

Revision 0

Page 11

(ASCII) files. With option 2, each record contains the same information as option 1. A third option is an ASCII file where each 80 -character record contains two sensor records.

Memory requirements and running times are similar to those for CDREV. Input instructions for using GUI.F and a detailed description of the output files are given in Appendix C.3.

\subsection{Program to Time Average Sensor Data, CGULF}

The CGULF program is similar to GULF in that the data base is accessed and data files are created. The key difference is that CGULF time averages sensor data over specified intervals of time, making it useful for smocthing noisy signals. The length of the averaging interval and the frequency of output are both input parameters. For example, the output could consist of sensor data averaged over a five minute interval each hour on the hour.

Another difference between GULF and CGULF is the content of the output when a standard FORTRAN binary or FORTRAN formatted output file (options 1 or 2 ) is specified. In these cases, CGULF writes out the observed standard deviation of each sensor in each averaging interval in addition to the five items in a GULF record. When output file format option 3 is called for, CGULF creates a file identical in content and format to GULF. Input instructions for CGULF and a detailed description of the output files are given in Appendix C.4.

\subsection{Programs to Summarize Pump Motor Operations, PUMPS and PMPRPT}

The PUMPS program summarizes the operating history of the primary and secondary loop pump motors. The operating time of each main motor in each of four pre-selected speed (pump RPM) ranges is accumulated and reported. Also tallied and reported is the operating time of each pony motor.

A file, pmphis, containing operating time accumulated from previous PUMPS runs is read and updated. The PMPRPT program, which can be run to produce summary reports, also reads the pmphis file. 
Input instructions for PUMPS and PMPRPT are given in Appendix C.5, along with the format and content of the pmphis file.

\subsection{PROGRAMS ACCESSING GULF AND CGULF GENERATED FILES}

The GULF and CGULF programs described in the previous section are used to retrieve and store specified subsets of the data base for later processing. General purpose programs that read these data files are described below.

\subsection{Program to Average Sensor Data, SENAV}

The SENAV program is designed to average sets of two or more sensors together and write the results on disk or tape in GULF format. The sensor data processed by SENAV are read from a single file created by GULF, CGULF or a previous SENAV run.

SENAV is typically used to average redundant sensors together or to average corresponding sensors in each of the three heat transport loops to yield reactor averages. SENAV input instructions are given in Appendix C.6. The program can optionally be instructed to discard from the averaging process sensor records that are flagged invalid or where readings fall outside specified limits. This feature was incorporated to provide a means of preventing a faulty sensor from invalidating the resulting averages.

\subsection{Program to Generate Plot Files, GPD}

The function of GPD is to read specified data from a GULF, CGULF, or SENAV (GULF-format) file and produce a complete input file for a plotting routine that is not available on the SUN workstations. However, GPD output files may be preferable to GULF-format ASCII files as input to standard plotting or spreadsheet programs.

Input instructions and the output file format for GPD are described in Appendix C.7. 


\subsection{Programs to Merge GULF-Format files, MERGF}

The MERGF program reads and merges two or more files generated by GULF, CGULF or SENAV. The resultant file contains all of the sensor records on the input files in proper time order. MERGF is also useful for concatenating or reformatting GULF-format files.

Instructions for using MERGF can be found in Appendix C.8.

\subsection{SUBROUTINE LIBRARY FOR DATA RETRIEVAL AND PROCESSING}

In the previous sections brief descriptions of complete programs for retrieving and processing FFTF data were given Also available is PODMLIB, a library of FORTRAN callable subroutines and functions through which a user's program and access and process FFTF data. All programs described in the previous sections call routines in PODMLIB.

A summary data retrieval subroutine in PODMLIB is given in Table 7-1 while other available subroutines and functions are summarized in Table 7-2. Instructions for using the routines in PODMLIB are given in Appendix $D$.

Table 7-1

Data Retrieval Subroutines in PODMLIB

Subroutine Name

OPENDF

INITFO

GETMSO

SKIT

\section{Function}

Opens data files assigned by REQFL

Positions files previously opened by OPENDF, sets up a table of sensors to be retrieved and performs other initializations

Retrieves data records in chronological order for sensors specified in call to INITFO

Repositions previously opened files to a specified time 
Table 7-2

Other Subroutines and Functions in PODMLIB

Subroutine

Name

CA2SN

NCODT

DECODT

KUNITS

ICOND

ISTATWD

IVALID

NEXTIM

IPAST

CLEAR/CLEARC

KRONO

TDIF

VERSN

\section{Function}

Converts a list of sensor identifiers (in ASCII) to a corresponding list of integers used internally in the data base to identify sensors.

Encodes a date and time (year, month, day, hours, minutes and seconds) into data base format.

Decodes a data base date and time word into six words (year, month, day, hours, minute and seconds).

Extracts the engineering units code from a data base record

Interprets the DDH\&DS status word and returns the status.

Returns a word containing the 16 DDH\&DS status bits.

Determines from a 16 bit status word whether a sensor record is valid or not.

Adds a time (hours, minutes, seconds) to a data base date and time word. The result is in data base format.

Subtracts a time (hours, minutes, seconds) from a data base date and time word. The result is in data base format.

Set all elements of a specified array to an initial value.

Determines the chronological order of two pair of date/time words in data base format.

Calculates the difference in seconds between two given dates/times.

Returns the version number and release date of PODMLIB. 


\subsection{REFERENCES}

1. J. V. Nelson, "The FFTF Plant Operational Data Management System," WHC-SD-FF-SWD-063, Rev. 0, released June 10, 1994.

2. Letter, T. A. Mangelsdorf to Director, FFTFPO, "Functional Requirements for FFTF Operational Data Management," 7952796, September 25, 1979.

3. S. A. Hunt and S. E. Busby, "Report on FFTF Site Computing Study," TC1071, Hanford Engineering Development Laboratory, April 1978.

4. Letter, T. A. Mangelsdorf to Director, FFTFPO, "FFTF Operational Data Management Plan," 7863267, October 6, 1978.

5. J. V. Nelson and M. R. Gilbert, "Users' Guide to the FFTF Plant Operational Data Management System," HEDL-TC-2506, January 1984.

6. Letter, T. A. Mangelsdorf to Director, FFTFPO, "FFTF Data Output Control and Cost," 7950990, March 1979. 


\section{APPENDIX A}

\section{Content of Sensor Records in the Operational Data Base}

Each data record in the FFTF Operational Data Base consists of 8 bytes (64 bits) containing the following information:

a sensor identifier, the sensor value in engineering units, a code indicating the units, the sensor status.

The engineering units codes are defined in Table A-1. The sensor status is given by a 16 bit status word. The meaning of each of the bits is defined in Table A-2. Only the first eleven status bits that are used are stored in the operational Jata base.

Associated with each data record is an 8 byte date and time entry that gives the time to the tenth of a second. FFTF plant clocks used to time-stamp each data record written to tape are set to local time -- either Pacific Standard Time (PST) or Pacific Daylight Time (PDT). The Operational Data Base uses a constant time base -- PST. When Daylight Time is in effect, recorded time values are converted from PDT to PST before entry into the data base.

The internal structure of the data base, and the format of the data records and date/time entries, which vary depending on whether they were written on the CRAY or a SUN, are described in detail in Reference 1. Regardless, data records are converted to an internal PODM format when they are read in. This format is described later in Appendix D, Section D.1.3. 
Table A-1

\section{Engineering Units Codes}

Code

01

02

03

04

05

06

07

08

09

10

11

12
Engineering Units

degrees Fahrenheit

ga] lons per minute

$10^{3}$ gallons per minute

counts per second

percent of full power

feet

inches

millirem per hour

decades per minute

revolutions per minute

pounds per square inch

pounds per square inch - gauge

relative weighting ( 0 to 1 )

volts a-c

counts per minute

hertz

value logic (0/1/2/3=moving/closed/open/invalid)

millivolts

PPS relay logic $(0 / 1=0$ en $/$ closed $)$

percent open

rad

megawatts thermal

dollars per hour

megawatt days

percent of full flow

kilowatts

cents

percent full

gallons per minute (approximate)

no units

hours

dollar

days

seconds

inches of water

percent of full flow pressure drop

megawatts

no units

no units

amperes

milliamperes
Abbreviation

In Printouts

DEG $F$

GPM

KGPM

CPS

$\%$ PWR

FEET

INCHES

MR/HR

DPM

RPM

PSI

PSIG

COEFF

VAC

CPM

$\mathrm{HZ}$

VLOGIC

MV

NLOGIC

$\%$ OPEN

RAD

MWT

\$/HOUR

MWDAYS

\% FLOW

KWT

CENTS

$\%$ FULL

AP-GPM

HOURS

DOLLAR

DAYS

SECOND

IN H2O

\%FFPD

MW

AMPS

MA 
WHC-SD-FF-CSUD-019. Revision 0

Page 18

Table A-2

DDH\&DS Status Bits

\section{DDH\&DS \\ Bit $\mathrm{NO}_{2}$}

1
2
3
4
5
6
7
8
9
10
11
$12-16$

\section{Meaning when bit is set $(=1)$}

high alarm limit exceeded low al arm limit exceeded invalid readings (2 consecutive) single invalid reading (noise)

al arm acknowledged

alarm logged

processing

1 imit checking

recorded

increased data rate

I/O active

Not Used

\section{Normal value}

0

0

0

0

0

0

1

1

1

1

a Bit $\# 1$ is the leftmost (highest order) bit in the word.

b Normal value of the 16 bit status word is 928 decimal. 


\section{APPENDIX B}

\section{Content of FFTF Operational Data Base}

A program, LSTMFD, is available to give a table of contents of the FFTF operational data base maintained in CFS. An example of the reports produced by LSTMFD is given in Table B-1. From such a table, a user can determine the time span included in the data base and also can determine how many files would be necessary to generate a particular report.

The LSTMFD program can be executed by entering:

/apps/sh/lstmfd

anywhere in either a batch or interactive run.

LSTMFD has four optional input data cards (lines) which are described in Table B-2. These cards are used to obtain a listing of only a specified subset of the available data files.

Another method for determining the number of files required to produce a report is to simply execute the REQFL program per instructions in Appendix C.1 in an interactive run. The REQFL program will indicate how many data files are required for a report. These files will be automatically assigned at that point. If the user does not want to assign the files, hit the Control and $C$ keys simultaneously immediately after the message, "X FILES CONTAIN REQUESTED DATA." 
Table B-1

Sample LSTMFD Report

CONTENTS OF FFTF OPERATIONAL DATA BASE ON 2-Jun-94 AT 09:19:16

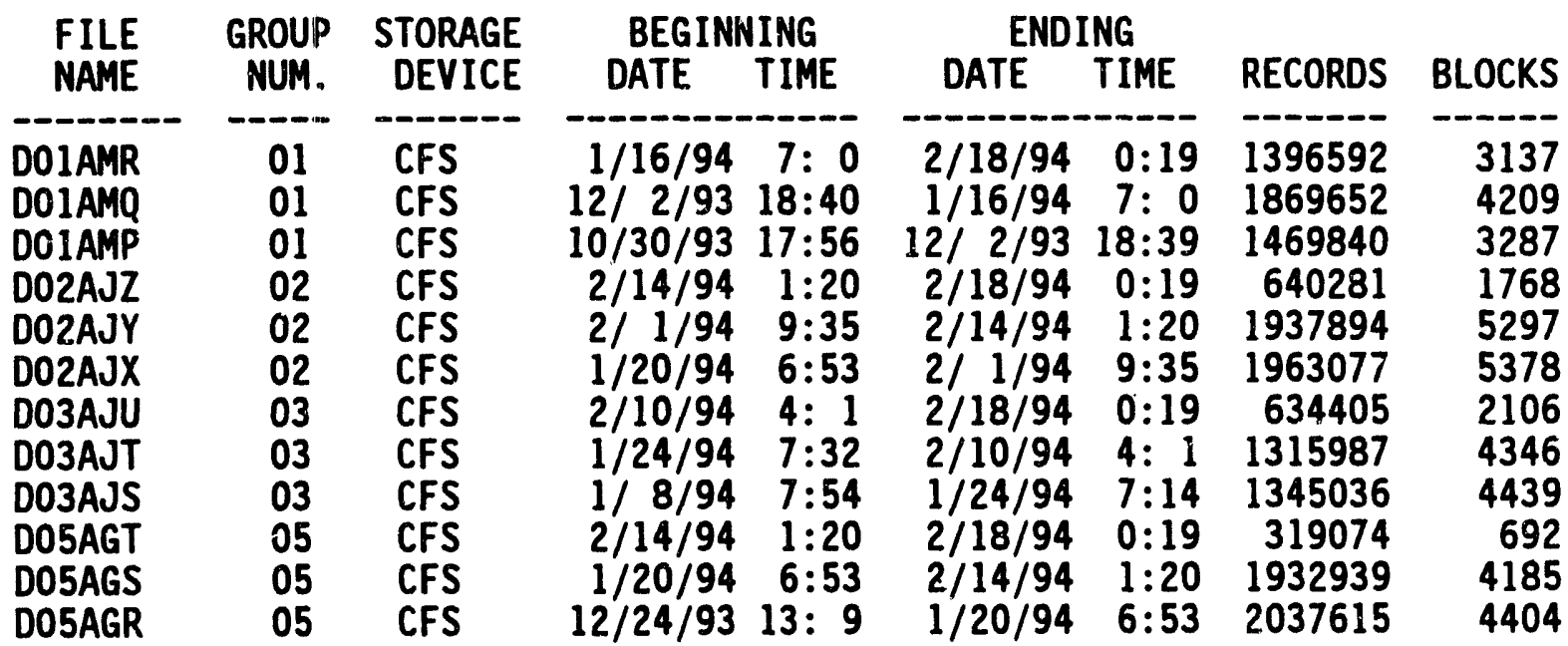

THIS IS A LIST OF THE MOST RECENT FILES FOR GROUPS: $12 \begin{array}{llll} & 2 & 4 & 5\end{array}$ 
Table B-2

\section{LSTMFD Input Cards}

Card 1: List type

Col. 1: Enter S, N, D or L.

$S$ will result in a list containing only

the three most recent files in each group.

$N$ will result in a list containing files

in the active library.

D will result in a list of files containing

data recorded between dates specified on Card 2 .

$L$ will result in a list containing files in both the active library and the archives.

Co1. 2: Enter $G$ or leave blank.

If $G$ is entered, only files for groups specified on cards 3 and 4 will be listed.

If Col. 2 is left blank, cards 3 and 4 are not read and a list containing files in all groups is produced.

Card 2:" Dates to be included in the report. The format is MMDDYY, MMDDYY. If the first entry (the starting date) is zero, then all files containing data up to the ending date (the second entry) will be listed. If the second entry is zero, then all files containing data from the starting date up to the present will be listed

Card $3:^{b}$ Total number of groups to be listed (free field format)

Card $4:^{b}$ Groups whose files are to be listed (free field format). The number of entries on this card is specified on Card 3.

a Card 2 is read only if colum 1 of card 1 contains a "D".

b Cards 3 and 4 are read only if Col. 2 of Card 1 contains a "G". 


\section{APPENDIX C}

\section{Instructions for Using Programs in the PODM Library}

Descriptions of available PODM programs, instructions for their use and examples are contained in this appendix. These programs that are operational on the SUN Workstations cesl and ces3 include:

$\begin{array}{ll}\text { REQFL } & (C .1) \\ \text { CDREV } & (C .2) \\ \text { GULF } & (C .3) \\ \text { CGULF } & (C .4) \\ \text { PUMPS } & (C .5) \\ \text { PMPRPT } & (C .5) \\ \text { SENAV } & (C .6) \\ \text { GPD } & (C .7) \\ \text { MERGF } & (C .8)\end{array}$

\section{C.1 Data File Assignment Routine, REQFL}

REQFL is used to assign and stage files containing the operational data for the sensors and time period required by a user. This routine must be executed prior to running PODM data retrieval programs or programs invoking the PODM data retrieval subroutines. REQFL requires less than $170 \mathrm{~K}$ bytes of memory and only a second of CPU time to execute. However, it could take 10 minutes to transfer each file from CFS. LSTMFD (Appendix B) can be used to determine how many files are required for a given run. To determine if any of the needed files already exist on SUN disk space, enter "1s/tmp/podm."

To run reqfl enter "/apps/sh/reqf1" and press the RETURN key. Then enter the REQFL input. A description of this input is given below in Section C.1.2. When executed in the interactive mode, the program will prompt the user for input. 


\section{C.1.1 Files Used by REQFL}

REQFL reads the user input described in Section C.1.2 from the standard input file (FORTRAN unit 5) and writes summary information to the standard output device (unit 6). REQFL also reads the master variable file (mvardic) and the master file directory (mfildir) through logical units 39 and 40 . The master variable file contains, for each valid sensor, the sensor name, the number of the group to which it belongs, a single digit number identifying the recording data system, and the number used to identify the sensor in the data base. A listing of a small part of mvardic is given in Table $C-1$. The master file directory contains, for each data file, the information displayed in Table B-1.

The format and content of mfildir and mvardic are described in detail in Reference 1. The location of these files is known to REQFL, and they are automatically assigned.

REQFL writes the list of commands to retrieve needed data files from CFS to file ASG_COM through unit 35. Also, a file, ASG_DATA, giving data directory names and listing basic information about each assigned data file, is written through unit 36 . Finally, logical units 41 through 60 are used for assignment of data base files and index files, as needed.

\section{C.1.2 Data Cards for REQFL}

Card 1: Access code. A11 facility and other unclassified data can be accessed by entering the master password in columns 1 and 2 . Experimenter-owned data that have been classified as proprietary* can be accessed by entering a code word of the form: XXGGYY, where $X X$ is the master password, $G G$ is a proprietary group number (two digits) and $Y Y$ is the special two-character passivord for group GG. Contact the PODM System custodian to obtain the required passwords.

* The control and distribution of data from instrumented tests are discussed in Reference 6 and Section 6 of El-504. 
WHC-SD-FF-CSUD-019

Revision 0

Page 24

Card 2: Group numbers or sensors required. Entries are in free-field format separated by one or more blanks or a comma and terminated by $\$$. Entries can be made in columns 1 through 72 only, but any number of cards (1ines) may be used. Group number are one or two digits.

Sensor identifiers consist of five or six alphanumeric characters. A mixture of group numbers and sensor identification numbers may be entered. Lists containing available sensors and their group numbers are also available from the PODM System custodian.

Card 3: Beginning and ending dates and times (MMDDYY HHMM, MMDDYY HHMM, Where MMDDYY is a six-digit entry for month, day and year and HHMM is a four-digit entry for hours and minutes on a 24-hour clock). In place of the beginning and ending dates and times, card 3 may also contain the entry CURRENTs if only the latest disk file for each specified group is wanted.

NOTE: Date and time entries should be in Pacific Standard Time.

\section{C.1.3 Examples of REQFL Input}

1. To assign files containing data on sensors 21047, 21011A and 21001A recorded between Nov. 3, 1989 at 6AM and Nov. 5, 1989 at 3PM:

MK

$$
2104721011 \text { A 21001A\$ }
$$

1103890600,1105891500

MK in the above example, and in other examples in this appendix, is assumed to be the master password.

2. To assign files containing group 1 data plus data for sensors R10801, $\mathrm{R} 10802$, and R10803 recorded on Jan. 30, 1989:

MK

$1, \mathrm{R} 10801, \mathrm{R} 10802, \mathrm{R} 10803 \$$

0130890000,0130892359 
Card 2 of this example is equivalent to:

$$
1, R 10801 \text { S }
$$

since $R 10801, R 10802$ and $R 10803$ are in the same group (i.e., on the same file).

3. To arsign the latest group 1 and group 2 files:

MK

1,25

CURRENTS.

4. To assign the necessary group 1 files and the group 13 proprietary files having a special password LM when data recorded between 0700 and 1300 (PDT) on May 15, 1990, are needed.

MK13LM

$1,13 \$$

$0515900600,0515901200$.

\section{C.2 The Correlated Data Report Generator, CDREV}

The CDREV program can be used in either the interactive or batch mode to produce correlated data reports as described in Section 5.2. Before CDREV can be executed, the REQFL routine must be run to assign the necessary data files. A complete batch run stream involving REQFL and CDREV can be found in Appendix E.

To run CDREV, enter:

/apps/sh/xqt cdrev

or

/apps/sh/xqt cdrev < in_file where in file is a file containing the data described in Section C.2.2. 


\section{C.2.1 Files Used by CDREV}

CDREV reads the input data described in section C.2.2 from the standard input file (logical unit 5). All output is written to the standard output device (unit 6). CDREV automatically assigns and reads several other files including:

* the ASG_DATA file, created by REQFL, through unit 36,

* a file named eunits through unit 34 ,

* the mvardic file (described in C.1.1) through unit 39,

* one or more data base files assigned by REQFL.

The eunits file contains a list of valid engineering units and their associated units codes (see Table A-1).

\section{C.2.2 Data Cards for CDREY}

The following information is read from the standard input file.

Card 1: Number of columns of output per page. Maximum value is 10. Recommended values are 10 for a full-width line printer, and six for 80 column screens.

Card 2: Beginning and ending dates and times to be included in the report. The format is:

MMDDYY HHMM, MMDDYY HHMM where MMDDYY is a six-digit entry for month, day and year and HHMM is a four-digit entry for hours and minutes on a 24-hour clock. NOTE: Date and time entries should be in Pacific Standard Time.

Card 3: Time interval between lines of output. The format is HHMMSS.T where $H H$ is hours, MM is minutes, SS is seconds and $T$ is tenths of a second. The input value, read as a free-field floating point number, must range between 0.1 ( $1 / 10$ of a second) and 240000.0 (24 hours). 
Card 4: List of identifiers for sensors to be included in the report. Entries must be separated by one or more blanks and/or a comma and terminated with \$. Only Columns 1 through 72 may contain input. More than one card (1ine) may be used with any number of sensor identifiers per card.

If more than one report is desired, repeat cards 2, 3 and 4 . If CDREV is run interactively, enter a line with 4 zeroes separated by commas or spaces to terminate.

\section{C.2.3 Examples of CDREV Input}

1. The input to produce a report on the behavior of sensors $21047,21011 \mathrm{~A}$ and 21001A between Nov. 3, 1989 at 6AM and Nov. 5, 1989 at 3PM, with a one-hour time interval between each line in the report is:

6

1103890600,1105891500

10000.0

21047 21011A 21001A\$

(assuming REQFL, example 1, has been run to assign the files).

2. The input to produce a report on sensors $\mathrm{C} 00000, \mathrm{C} 00014, \mathrm{C} 00010, \mathrm{C} 00001$, R10801, R10802 and R10803 on Jan. 30, 1989 between 10AM and 11AM with a one second time interval between print lines is:

6

0130891000,0130891100

1.0

C00000,C00014,C00010,C00001,R10801,R10802,R10803\$

(assuming REQFL, example 2, has been run to assign the necessary files).

3. The input to produce a by-the-minute record on sensors $10001 \mathrm{~A}, 10101$ and C10001 from data on the latest disk files is:

6

0101790000,1231992359

100.0 


\section{$10001 \mathrm{~A}, 10101, \mathrm{C} 10001 \mathrm{~S}$}

(assuming REQFL, example 3 , has been run to assign the disk files). Note, a wide time range on card 1 was used to be assured of getting all the data on the files without having to know what dates/times are included on the latest files.

\section{C.3 Program to Generate User Files, GULF}

The GULF program allows the creation of special user-owned files containing selected subsets of the operational data base. A primary application of this program has been in sending data to users in computer readable form. Also, programs such as MERGF and SENAV read GULF generated files. A typical runstream for GULF is:

/apps/sh/reqf1 « EOI

[Input for REQFL defined in Appendix C.1.2]

EOI

/apps/sh/xqt gulf <<EOI

[Input for GULF. See Section C.3.2].

EOI

mv senout perm_file

where perm_file is the name of the file, in which the GULF output is to be permanently stored (see sections C.3.1, C.3.2 and C.3.3).

\section{C.3.1 Files Used By GULF}

GULF reads input data described in section C.3.2 from the standard input file (logical unit 5). Summary information is written to the standard output device (unit 6). However, the main GULF output (i.e, requested sensor records) is written to file senout through logical unit 10. Like CDREV, GULF automatically assigns and reads several other files, including ASG_DATA, mvardic, and one or more data base files. 


\section{C.3.2 GULF Input Instructions}

The following information is read from the standard input file.

Card 1: Structure of output file. Enter 0,1 or 2 in Col. 1.

0 - FORTRAN binary file.

1 - Standard FORTRAN formatted (ASCII) file containing one data record per line

2 - Packed ASCII file containing two data records per line.

See section C.3.3 for details on the file formats.

Card 2: Beginning and ending dates and times of data to be included in output file. The format of this card is:

MMDDYY HHMM, MMDDYY HHMM

where MMDDYY is a six-digit entry for the month, day and year and HHMM is a four-digit entry for hours and minutes on a 24-hour clock using Pacific Standard Time.

Card 3: Time interval for output of sensor data (HHMMSS.T, where HH is hours, MM is minutes, SS is seconds and $T$ is tenths of seconds). If the entry, which is read as a floating-point number in free-field format, is less than or equal to 0.1 , all data are written. Otherwise, only one record for each sensor in each time interval is written.

Card 4: List of identification numbers for sensors to be included in the output file. Entries should be separated by one or more blanks and/ or a comma and terminated with $\$$. Only Columns 1 through 72 may be used. More than one card (line) may be used with any number of sensor identifiers per card.

\section{C.3.3 Format of Output Files}

In all cases, the information written for each sensor recording consists of the date and time, the sensor identifier, a floating point value for the 
sensor, an integer number indicating the units of the floating point value and the DDH\&DS status word. The engineering units codes are defined in Appendix A.

The DDH\&DS status word in GULF output records is an integer with value ranging from 0 to 65504. To interpret the status word, first convert it to a 16 bit binary number. Label the 16 bits from 1 to 16 with the most significant (leftmost) bit being 1. Then refer to Table A-2 in Appendix $A$ to interpret the status bits. The bit numbers, as identified above, are listed in column 1 of this table.

As an example, suppose the status word in a GULF file has a value of 12288. The binary representation of this number is:

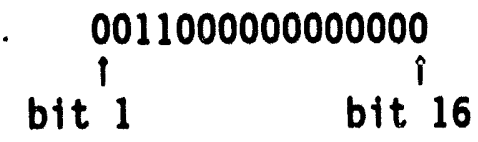

In this is case, bits 3 and 4 are set. From Table A-2 it can be seen that these bits indicate the occurrence of invalid readings.

Use of the "0" option for data output results in the generation of a standard FORTRAN binary file. Each logical record described in Table C-1 contains the data for one sensor at one time period. Use of the "1" option results in the generation of a standard FORTRAN formatted (ASCII) output file. Each record (1ine) consists of 41 characters as shown in Table C-2. Use of the "2" option also results in the generation of an ASCII file. However in this case, two sensor records are stored in each character line, as shown in Table C-3. 
WHC-SD-FF-CSUD-019.

Revision 0

Page 31

Table C-1

Content of Gulf Records Written to a FORTRAN Binary File* (Option 0 )

Word

Content

1 The date, a six-digit integer value (YYMMDD, where YY is the year, MM is the month, and DD is the day)

2 The time of day to the $1 / 10$ second, a seven digit integer (HHMMSST, where HH is the hours on a 24-hour clock, MM is the minutes, $S S$ is the seconds and $T$ is the tenth of seconds)

3 The sensor identifier (6 characters)

4 Sensor value in engineering units (a floating point word)

5 Units code (see Appendix A)

6 The 16-bit DDH\&DS status word right justified in the 32-bit integer word

* The WRITE statement used to create the FORTRAN binary files is of the form:

WRITE(8) NDT, NTM, IDSEN, VAL, IUNITS, ISTAT 
WHC-SD-FF-CSUD-019

Revision 0

Page 32

Table C-2

Content of Gulf Records Written to a FORTRAN Formatted File* Using Option 1

Characters

$1-6$

7

$8-14$

15

$16-21$

22

$23-32$

33

$34-35$

36

$37-41$

Content

The date (YYMMDD, where YY is the year, MM is the month and $D D$ is the day)

blank

The time of day to the $1 / 10$ second (HHMMSST, where HH is the hours on a 24-hour clock, MM is the minutes, SS is the seconds, and $T$ is the tenths of seconds)

blank

Sensor identifier

blank

Sensor value in engineering units. The floating point format is: $\pm x . x x x E \pm y y$

blank

The units code (see Appendix A)

blank

The integer value of the 16-bit DDH\&DS status word (see Appendix A)

* The WRITE and FORMAT statements used to create the formatted files are:

WRITE $(10,10)$ NDT, NTM, IDSEN, VAL, IUNITS, ISTAT

10

FORMAT $(16,1 \mathrm{X}, 17,1 \mathrm{X}, \mathrm{A}, 1 \mathrm{X}, 1 \mathrm{PE} 10,3,1 \mathrm{X}, 12,1 \mathrm{X}, \mathrm{I5})$ 
Table C-3

Content of GULF Records Written to a Packed ASCII File Using Option 2

Columns

$1-6$

$7-13$

14

$15-20$

$21-30$

31

32 - 33 Units code (see Appendix A)

34

blank

35 - 39 Integer value of the 16-bit DDH\&DS status word (see Appendix A)

40

blank

$41-80$

Content

The date (YYMMDD, where YY is the year, MM is the month and $D D$ is the day)

The time of day to the $1 / 10$ second (HHMMSST, where HH is the hours, MM is the minutes, SS is the seconds and $T$ is the tenths of seconds)

blank

Sensor identifier

Sensor value in engineering units. The floating point format is: $\pm x . x x x E \pm y y$.

blank

Same as col.s $1-40$ for the second sensor record on a card image 


\section{C.4 Program to Produce Files of Time-Averaged Data, CGULF}

The function of CGULF is to produce files containing time-average sensor data. As with the GULF program (Appendix C.3), the total time span to be covered and the frequency at which sensor records are written out are user specified. The output frequency in CGULF determines the time step between successive calculations of sensor averages. In addition, the length of averaging interval must be specified. For example, if the output frequency is set to one hour and the averaging interval is set to five minutes, all sensors specified will be averages over a five minute period each hour.

Other CGULF input items include, for each sensor, the type of data validity checking to be performed and the DDH\&DS scan interval. The data checking options are included because a single bad sensor signal will result in an erroneous average if it is not screened out.

Three options are available:

- no data checking

- use of the data validity flags in the DDH\&D status word (discussed in Appendix A)

- input of an acceptable range for a sensor reading

When the third option is selected, upper and lower limits must be read in. If a sensor value retrieved from the data base does not fall between these limits, that value is rejected and not used in the sensor averaging process.

When the second option is selected, the DDH\&DS status word in each retrieved sensor record is checked. If either of the validity flags (bits 3 and 4 ) are set, the record is rejected. Also, records of PDS origin are rejected if either the "processing" bit (7) or their "I/0 active" bit (11) is not set to 1.

If the first option is specified, all sensor records retrieved from the data base are used in computing time averages. 
In most CGULF runs, a number of sensors will be called for. Since data checking option is specified for each sensor, more than one option can be specified in a single run.

The DDH\&DS scan rates are used only in the computation of the standard deviations. The scan rates are needed because the DDH\&DS uses a data compression scheme to reduce the volume of data recorded. If a value acquired by the DDH\&DS for a particular sensor differs from the last recorded value for that sensor by less than a specified amount (a compression window), the current value is not recorded. Each sensor is, however, recorded at least once per hour, even if it is constant. The compression windows, which normally range from $0.2 \%$ to $3 \%$ of full scale, are listed in the variable description table available from the PODM System custodian. This table gives the sensor scan rates needed to compute the standard deviations. Since small data fluctuations are not recorded due to data compression, the standard deviations computed will normally be slightly low.

A typical CGULF runstream is given below:

/apps/sh/reqf1 $\ll$ EOI

[data cards for REQFL defined in Appendix C.1.2]

EOI

/apps/sh/xqt cgulf $\ll$ EOI

[data cards for CGULF. See Section C.4.2].

EOI

mv senout perm_file

\section{C.4.1 Files Used By CGULF}

CGULF used the same files as GULF (see section C.3.1).

\section{C.4.2 Input Instructions}

Card 1: Structure of output file. Enter 0,1 or 2 in Col. 1. $0=$ FORTRAN binary file.

- 1 = Standard FORTRAN formatted (ASCII) file. 
2 = Packed ASCII file containing two sensor records per line. (See section C.4.3.)

Card 2: Beginning and ending dates and times of data to be included in output file. The format of this card is:

MMDDYY HHMM, MMDDYY HHMM where MMDDYY is a six-digit entry for the month, day and year and HHMM is a four-digit entry for hours and minutes on a 24-hour clock using Pacific Standard Time.

Card 3: Two entries in free field format.

Item 1 -- Frequency for computing averages and writing sensor data (HHMMSS.T, where HH is hours, MM is minutes, SS is seconds and $T$ is is tenths of seconds).

Item 2 -- Length of each averaging interval (HHMMSS.T). This time interval must be between 0.1 seconds and the time step specified in item 1.

Card 4: List of identification numbers for sensors to be included in the output file. Entries should be separated by one or more blanks and/or a comma and terminated with \$. Only Cols. 1 through 72 may be used. More than one card ( 1 ine) may be used with any number of sensor identifiers per card. The number of sensors must be less than 800 .

Card 5: The DDH\&DS scan rate (seconds) for each sensor given in Card 4 (decimal numbers in free-field format).

Card 6: The type of data rejection criteria to be used for each sensor given in card 4 in free field integer format.

$0=$ No test (accept all data records)

1 = Reject all data records $f 1$ agged in the DDH\&DS status word as being invalid

2 = Read sensor limits and reject all sensors values outside these limits 
Card 7: The low limit for data acceptability. One entry is required for each sensor having a type 2 data rejection criterion on Card 5. Data are read in free-field floating point format.

Card 8: The high limits for data acceptability. One entry is required for each sensor having a type 2 data rejection criterion. Data are read in free-field floating point format.

Note: Cards 7 and 8 are read only if type 2 data checking is specified for one or more sensors.

\section{C.4.3 Format of Output Files}

The content of CGULF output files is the same as GULF files (section C.3.3) except that:

1) the status word is set to zero in all cases, and

2) the standard deviation of sensor data is added to the output records if FORTRAN binary or standard FORTRAN formatted files are specified (options 0 or 1 ).

CGULF records then consist of:

1) the date and time at the beginning of an averaging interval

2) sensor identifier

3) a time averaged sensor value in engineering units

4) the units code

5) a zero entry in place of the status word to preserve compatibility with GULF records

6) the standard deviation of sensor data over the time interval

As in GULF, there are three options for the format of the output files: FORTRAN binary, Standard ASCII, and packed ASCII. Because the formats available in CGULF are nearly identical to those in GULF, only the differences are identified here. 
WHC-SD-FF-CSUD-019

Revision 0

Page 38

A GULF Binary output record consists of six words as given in Table C-1. CGULF binary records contain these six words plus a seventh word representing the standard deviation. A GULF standard ASCII record consists of the 41 characters described in Table $\mathrm{C}-2$, plus the standard deviation in character positions 42 through 52. A CGULF packed ASCII record does not contain a standard deviation entry. Thus, a CGULF packed ASC.II file is identical in format to a GULF packed ASCII file (Table C-3).

Even though there are differences between CGULF and GULF output files, programs that required GULF-format files as input (e.g. SENAV, GPD, and MERGF) also will read CGULF files without any difficulty.

\section{C.5 Programs to Summarize Pump Motor Operations, PUMPS and PMPRPT}

The PUMPS program summarizes the operating times of the primary and secondary loop pumps in seven selected speed (RPM) ranges. The program assumes that the first range specified defines the pump speeds expected when the pump motors are not operating. This range typically is from a small negative number (e.g., -10 RPM) up to the lower limit expected when a pump is operating on its pony motor.

The second speed range is assumed to define the pumps speed range when operating on pony motors. The third range is assumed to be an interval of undefined operation between pony and main motor speed ranges. The lower limit of this range should be set to the upper limit of pump speed while operating on the pony motor. The upper limit of this interval should be the lower limit of pump speed on the main motor.

The last four ranges are assumed to encompass pump speed range on the main motor. A complete set of ranges is read for each pump. 
A typical runstream for PUMPS is:

cd / tmp/podmwd \#Change to a working directory

[Commands to copy pmphis (see Section C.5.1) into the working directory] cp pmphis pmphis.old \#Save copy of pmphis before updating /apps/sh/reqf1 《 EOI

[Input for REQFL defined in Section C.1.2]

EOI

/apps/podm/bin/pumps.x $\ll$ EOI

[Input for PUMPS. See Section C.5.2]

EOI

nl pmphis \#list updated pmphis file

[Commands to copy pmphis back to a permanent storage location.]

\section{C.5.1 PUMPS files}

PUMPS reads the input data described in Section C.5.2 from the standard input device. An ASCII file, pmphis, is also read and updated. This file is used to accumulate pump operating data (the total operating time in each speed range for each pump). The format of pmphis is given in Table C-4. Updates made to pmphis during a PUMPS run are based on data records (pump speed versus time) read from one or more operational data files assigned by REQFL. PUMPS rejects records read from the operational data files if they are flagged as invalid by the DDH\&DS.

The PUMPS standard output (print) file lists the data read from pmphis, and the results after adding in the data from the operational data files.

\section{C.5.2 PUMPS Input}

PUMPS reads the following input from the standard input device. Table C-5 lists the input for a typical case. 
Card 1: Beginning and ending dates and times of data to be processed. The format of this card is:

MMDDYY HHMM, MMDDYY HHMM

As in Card 2 of Sections C.2.2, C.3.2, and C.4.2.

Card 2: Data retrieval time interval. The format is HHMMSS.T, as in Card 3 of Sections C.2.2 and C.3.2. A typical value is 500.0 .

Card 3: List of identifiers for pump speed indicators, separated by one or more blanks and/or a comma, and terminated with $\$$. The usual list of six identifiers is given in Table C-5.

Card 4: Lower and upper RPM limits of each of the seven speed ranges for the pump associated with the first identifier on Card 3. Seven pair of floating point numbers are read in free-field format. Repeat Card 4 for the other identifiers on Card 3.

Normal entries for Card 4 are given in Table C-5. Note that there are slightly different entries for the primary and secondary loop pumps.

Card 5: Pump motor associated with each of the seven speed ranges. Each entry begins on a separate line starting in column 1 . See Table C-5 for the normal Card 5 input.

\section{C.5.3 Description of PMPRPT}

PMPRPT reads the pmphis file through the standard input device and produces a one-page summary report of pump motor operating times. After reading pmphis, PMPRPT will optionally read one or more records of text information that is included in the output Table as foot notes. The summary report is written to the standard output file. A typical UNIX script for a PMPRPT run is given in Table C-6. 
Table $\mathrm{C}-4$

Format of File pmphis

Record

1

2

3

\section{Description}

Ending date and time of most recent PUMPS run. The format, starting in column 1 , is:

\section{YYMMDD HHMMSST}

where $Y Y, M M$, and DD are 2 digit entries for the year, month, and day, respectively, and HH, MM, SS, and $T$ is the time (hours, minutes, seconds, and tenths of a second, respectively).

Total operating times (hours) of pump 1 motors ( 6 entries in free field format):

1. Pony motor total

2. Main motor, first speed range

3. Main motor, second speed range

4. Main motor, third speed range

5. Main motor, fourth speed range

6. Main motor, tota $7^{b}$

Record 2 is repeated for each of the other pumps.

Status code for each pump at the end of the most recent PUMPS run. The status codes (in free field format) can have the following values:

$$
\begin{aligned}
& 0 \text { - no valid records read } \\
& 1 \text { - motors not operating } \\
& 2 \text { - pony motor operating } \\
& 3 \text { - RPM in undefined range } \\
& 4 \text { - main motor operating in range } 1 \\
& 5 \text { - main motor operating in range } 2 \\
& 6 \text { - main motor operating in range } 3 \\
& 7 \text { - main motor operating in range } 4 \\
& 8 \text { - Pump overspeed }
\end{aligned}
$$

a PUMPS writes operating times to the nearest 0.01 hours.

b Because of initialization of the pmphis file, the sum of main motor operating times in the four speed ranges may not equal the main motor total hours. 
Table C-5

\section{Iypical PUMPS Input}

04019300000101990000

500.0

$21047,22047,23047,21538,22538,23538 \$$

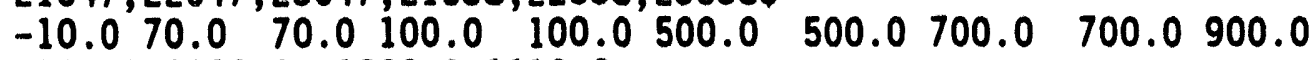

$900.0 \quad 1000.0 \quad 1000.0 \quad 1110.0$

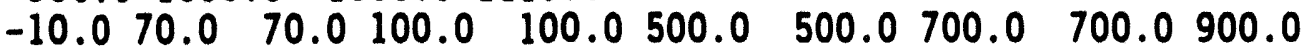

$900.0 \quad 1000.0 \quad 1000.01110 .0$

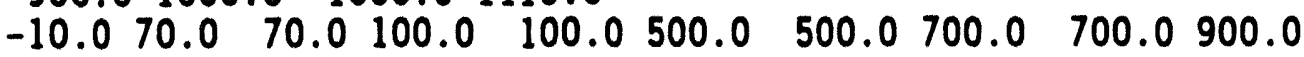

$900.0 \quad 1000.0 \quad 1000.01110 .0$

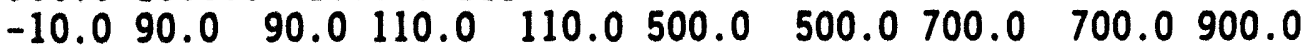

$900.0 \quad 1000.0 \quad 1000.01110 .0$

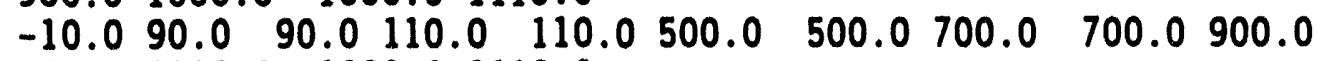

$900.0 \quad 1000.0 \quad 1000.01110 .0$

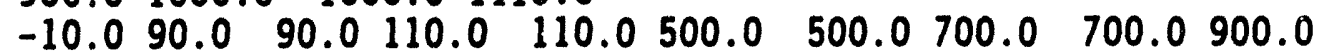

$900.0 \quad 1000.0 \quad 1000.01110 .0$

OFF

PONY

UNDF

MAIN

MAIN

MAIN

MAIN

Table C-6

\section{Iypical PMPRPT Runstream}

cd /tmp/podmwd

cP pmphis PMPRPT. INP

cat $\gg$ PMPRPT. INP $<<E O I$

Operating times given for each of the four main motor speed ranges include only data since $3 / 13 / 81$. Main and pony motor totals are for the lifetime of the pumps.

On $6 / 3 / 82$ at $1430 \mathrm{hrs}$ PDT, Pl main motor replacement was completed. At that time, $\mathrm{Pl}$ main motor operating totals were:

$$
\begin{aligned}
500-700 \mathrm{RPM} & =16.39 \mathrm{HRS} \\
700-900 \mathrm{RPM} & =162.45 \mathrm{HRS} \\
900-1000 \mathrm{RPM} & =1698.77 \mathrm{HRS} \\
1000-1100 \mathrm{RPM} & =950.35 \mathrm{HRS} \\
\text { MAIN TOTAL } & =9194.93 \text { HRS }
\end{aligned}
$$

EOI

/apps/podm/bin/pmprpt.x < PMPRPT. INP

rm PMPRPT. INP 


\section{C.6 Program for Averaging Sensor, SENAV}

SENAV is used to average data from two or more (usually redundant or similar) sensors. The results are written to a file, senout, in GULF format. SENAV reads the data described in section C.6.1 from the standard input file (unit 5). Sensor records to be averaged are read from a single GULF format file, seninp.

A typical SENAV runstream includes the following:

[Instruction(s) for linking or copying file seninp into the user's working directory.]

/apps/sh/xqt/senav « EOI

[SENAV input data described below]

EOI

mv senout perm_file

The last line in the runstream is an example of one way to move (rename) the output file, senout, to a permanent file.

\section{Input Data}

Card 1: Four entries in free field format:

1) Number of averages to be made $(\leq 30)$

2) Input file type ( 0 = binary, $1=$ FORTRAN formatted)

3) Output file type ( 0 = binary, $1=$ FORTRAN formatted)

4) Output option ( 0 = write out only the averages, $1=$ write out the averages plus all sensor data used in computing the averages)

Card 2: The identifiers for each average. Identifiers must be six characters or less in length separated by a comma or space and terminated by "\$". Only columns 1-72 may be used, but multiple lines are permitted. The number of identifiers expected is the value of entry 1 on Card 1.

Card 3: The lower acceptance limit for the sensor data used in computing each average, in free field format. One entry is read for each average 
called for on card 1, entry 1.

Card 4: The upper acceptance $1 \mathrm{imft}$ for sensor data used in computing each average. If a sensor value is outside the acceptance range, that input record is rejected and not used in the averaging process.

Card 5: The identifiers for all sensors to be used in computing the first average. Entries must be separated by a comma or space and terminated with "\$".

Repeat Card 5 for all averages called for on Card 1, entry 1.

\section{C.7 Program to Generate Plot Files, GPD}

GPD was designed to read a user file containing sensor data and generate an input file for a plot program that is not available on SUN Workstations. GPD may still be useful for generating files for importing to a spreadsheet or general purpose plot program. GPD reads data from a GULF-format file (seninp) and generates a file (pdatout) for one or more plots, each containing up to nine curves.

\section{GPD Input Instructions}

The following information is read from the standard input device (unit 5).

Card 1: Beginning date and time on the plot (MMDDYY HHMM) where MMDDYY is a six digit number representing the month, day and year, and HHMM is a four digit number representing the time (hours and minutes) on a 24hour clock.

Card 2: Length of plot in units of seconds, minutes, hours or days (for example, 7 DAYS). A space must appear between the numerical value and the units. The time units may be abbreviated as follows:

$$
\begin{aligned}
& \text { SECONDS - SEC, S } \\
& \text { MINUTES - MIN, M }
\end{aligned}
$$


HOURS - HRS, H

DAYS - DYS, D

Card 3: Four entries in free field format.

1) The number of points to be plotted for each sensor. If a value of 0 is entered all avallable data will be plotted. If a positive value, $N$, is entered the time axis will be divided into $\mathrm{N}$ equal intervals and all available data in each interval will be averaged to obtain a single data point for each interval. If no input data points exist in an interval, the last input value read will be used for that interval. A maximum of 1000 points can be plotted.

2) Input file type ( 0 - binary, 1 = FORTRAN formatted) as described in C.3.3.

3) Plot type (not used - enter 0 ).

4) Data rejection criterion (0 = accept all data, $1=$ reject all data $f$ lagged by the DDH\&DS as being invalid, 2 = reject data that are off-scale, 3 = read validity limits for each sensor to be plotted.

Card 5: Identifiers for each sensor to be included on this plot. Identifiers must be separated by a comma and/or one or more spaces and terminated with "\$". More than one line may be used. Columns 73-80 are ignored.

Card 6: Read only if entry 4 on card 3 was "3". The lower and upper validity limits for each sensor in free field format. Limits are read in pairs for each sensor. If a sensor value is outside the validity limits, it is ignored.

Card 7: Plot title -- 40 characters or less terminated with "\$". 
Card 8: Plot subtitle -- 40 characters or less terminated with "\$". Up to three subtitles can be entered.

\section{C.8 Progran for Merging or Concatenating GULF Format Files, MERGF}

MERGF provides the means to merge or concatenate GULF-format files. The UNIX cat utility can also be used to concatenate ASCII files, but not binary files. MERGF can also be used to change the format of a GULF file (e.g. from binary to ASCII). In some large data retrieval tasks, it is impossible to complete the job in a single run because the required data are spread over a large number of data base files. A solution to this problem is to make a series of GULF runs to retrieve all required data, and then run MERGF to merge the separate GULF files onto a single file.

\section{C.8.1 Files Used by MERGF}

MERGF writes sensor records to a GULF-format file, senout, through logical unit 10. Up to 10 GULF-format files can be read in a single run. A typical MERGF runstream includes the following sequence of control statements and data entries:

[Instruction(s) for assigning first input file to senin1] [Instruction(s) for assigning second input file to senin2]

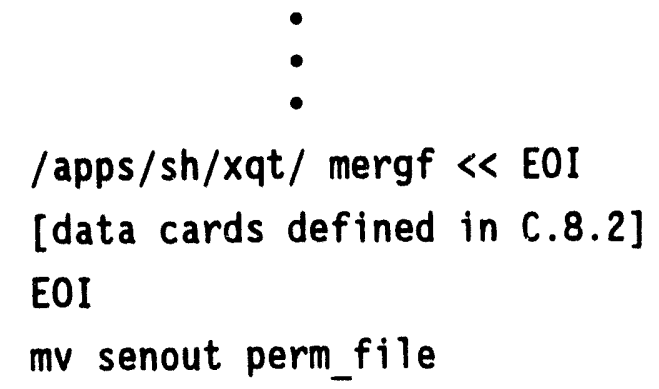

\section{C.8.2 Input Instructions}

MERGF input is consistent, as far as possible, with GULF input. Some details associated with the input items listed below are omitted here, but can be found in C.3.2. The following information is read from the standard input device. 
rd 1: Type of each input file in free field format ( 0 - binary, 1 = FORTRAN formatted). Enter one value ( 0 or 1$)$ for each input file. Note: packed ASCII files cannot be read.

ard 2: Output file type $(0,1$ or 2) in free field format. $(0=$ binary, $1=$ standard FORTRAN formatted, 2 = packed ASCII)

ard 3: Beginning and ending date and time of data to be retrieved (MMDDYY HHMM, MMDDYY HHMM) 


\section{APPERDIX D}

\section{Instructions for Using the PODM Subroutine Library, PODMLIB}

A subroutine library, podm1b.0, maintained in SUN directory /apps/bin is available to facilitate retrieval, encoding, decoding, and processing of information from the operational data base by a user's program. All routines in the library were written in FORTRAN 77. The library can be obtained by adding /apps/bin/podmib.o to the list of parameters passed to the FORTRAN computer (f77). For example, the command:

$f 77$-o gulf.x -03 gulf.f /apps/bin/podmlb.o

would compile source file gulf.f, link the PODMLIB library and create an executable file gulf.x.

\section{D.1 Data Retrieval Subroutines}

Four subroutines are described in this section. Three (OPENDF, INITFO, and GETMSO are required in order for a FORTRAN program to retrieve information from the operational data base. The fourth, SKIT, which is optional, was designed to efficiently locate sensor data when relatively long retrieval intervals (> 5 minutes) are called for.

Before a program can access the operational data base, REQFL must be run to assign the necessary data files. Subroutine OPENDF is called once to open the data files assigned by REQFL. Subroutine INITFO positions the data files assigned by REQFL to a specified initial date and time. Generally, INITFO, which must be called after OPENDF, is referenced only once in a program, but can be called whenever the files need to be repositioned to a new initial date and time.

Subroutine GETMSO controls the actual data retrieval. Each call to GETMSO, which is supplied with a list of required sensors, results in one sensor record being returned, unless there are no more data. Sensor records are returned strictly in chronological order rather than being ordered by sensor. Any required sorting of the retrieved data by sensor is left to the user. 
Subroutines OPENDF, INITFO and GETMSO and other PODMLIB routines that they call require $36 \mathrm{k}$ bytes.

Subroutine SKIT positions the assigned operational data files to a specified date and time. It is generally called after all data for one time interval have been retrieved. SKIT is then used to position the files at the start of the next interval. It is not necessary to use SKIT, but it can greatly reduce retrieval time, particularly with retrieval intervals of one hour or more. Its use is recommended for retrieval intervals over five minutes.

All parameters listed in the following sections are 32 bit integer or floating point words unless specified otherwise.

\section{D.1.1 Subroutine OPENDF}

\section{Function}

OPENDF reads a communication file ASG_DATA created by REQFL and opens the files assigned by REQFL.

\section{Usage}

CALL OPENDF (JPR).

\section{Parameters}

JPR Flag indicating if a summary of assigned files is to be printed. If JFLAG $=1$, the summary is printed; otherwise, it is not.

PODMLIB routines called

CLEAR, CLEARC, DECODT, NORMDT 
WHC-SD-FF-CSUD-019

Revision 0

Page 50

\section{D.1.2 Subroutine INITFO}

Function

The primary function of INITFO is to position the data files to a specified initial date and time. It also performs initialization and setup task. OPENDF must be called prior to INITFO.

Usage

CALL INITFO (JITIM, JLTIM, JNSEN, JISEN).

Parameters

JITIM Initial date and time for data retrieval coded in data base format.

JLTIM Ending date and time for data retrieval coded in data base format.

JNSEN Number of sensors for which data are to be retrieved.

JISEN An array containing the 5 or 6 character identifier name of each sensor.

Notes

The initial and final dates and times (JITIM and JLTIM) must be coded into the operational data base format prior to calling INITFO. PODMLIB routines NCODT (Appendix D.2.2) is available to perform the necessary encoding.

PODMLIB routines called

CA2SN, CLEAR, KRONO, LHASH, POSIT, PREPDF 


\section{D.1.3 Subroutine GETMSO}

\section{Function}

GETMSO accesses the assigned data files and returns a record for one sensor from the 1ist specified in the call to INITFO. Each call to GETMSO results in the next requested record being returned in chronological order.

\section{Usage}

CALL GETMSOMREC, ISQ)

\section{Parameters}

MREC Four-word array (32 bits/word) containing the returned sensor record. The content of each 32-bit word is:

1. The date, formatted as described in Table $D-1$.

2. The time - the number of $1 / 10$ seconds since midnight (0$863,999)$.

3. The sensor value in engineering units (an IEEE floating point word).

4. The units code, status bits and sensor number (see Table D-2).

ISQ An integer value returned by GETMSO indicating the position in the sensor list occupied by the sensor for which data were returned in MREC. (The sensor list is defined in a call to INITFO.)

\section{Notes}

The first call to GETMSO must be preceded by calls to OPENDF and INITFO. Because the ordering of data records returned on successive calls to GETMSO is strictly chronological, the sensor returned on a particular call could be any one in the list specified in the call in INITFO. The identity of the record can be determined from the ISQ parameter. It can also be determined by decoding $\operatorname{MREC}(4)$. 
If a program continues calling GETMSO until no more data are left on the file, MREC(1) and $\operatorname{MREC}(2)$ are set to FFFF base 16 (65,535 decimal) and $\operatorname{MREC}(2)$ is set to zero.

\section{PODMLIB routines call}

GETNXØ, KRONO

\section{D.1.4 Subroutine SKIT}

\section{Function}

SKIT positions assigned operational data files to a specified date and time. Before SKIT can be used, OPENDF and INITFO must be called.

\section{Usage}

CALL SKIT (NEXT)

\section{Parameters}

NEXT Two word array containing the date and time to which the data files are to be positioned. This date and time are coded as described in Section D.1.3 and Table D-1.

\section{PODMLIB routines called}

FREEFL, KRONO, POSIT, SWIFL

\section{D.2 Other PODMLIB Routines}

In addition to the data retrieval routines described in Section D.1, there are a number of other PODMLIR routines that are essential or may be useful in writing programs related to the PODM System. For example, NCODT, described in D.2.1, is required by programs that actually retrieve sensor records from the operational data base.

The following sections also describe other useful PODMLIB routines. Not all routines in PODMLIB are described below, or in D.1. These routines are calied by other PODMLIB routines, and hence program designers normally do not need to 
know what they do, or how to use them. However, if needed, a11 PODMLIB routines are listed in Reference 1.

\section{D.2.1 Subroutine CA2SN}

\section{Function}

Given a list of sensor identifers, CA2SN returns a list of corresponding sensor numbers (integers) obtained from the mvardic file described in Ref. 1.

\section{Usage}

CALL CA2SN(IDA, ISN, NSEN)

\section{Parameters}

NSEN Number of sensor identifiers in IDA.

IDA List of sensor identifiers. IDA is an array of six character variables.

ISN List of sensor numbers (integers) corresponding to each entry in IDA. ISN is a one-dimensional integer array with NSEN entries.

Notes

Data retrieval subroutines require the integer sensor numbers. INITFO calls CA2SN to generate this list given a list of user-specified sensor names.

\section{D.2.2 Subroutine NCODT}

\section{Function}

NCODT codes a date and time into an internal PODM date and time word.

Usage

CALL NCODT (IYR, IMO, IDY, IHR, IMI, SEC, NDT) 


\section{Parameters}

NDT Two word array word containing the date and time coded in the internal PODM format (Section D.1.3 and Table D-1) by NCODT.

IYR Year

IMO Month

IDY Day of month

IHR Hours on a 24-hour clock

\section{IMI Minutes}

SEC Seconds (a floating point word)

\section{Notes}

The INITFO subroutine required for data retrieval has as two of its parameters, the beginning date and time and the ending date and time for data retrieval. The date and time parameters must be in internal PODM representation. NCODT can be used to make the necessary conversions.

\section{D.2.3 Subroutine DECODT}

\section{Function}

DECODT decodes an internal PODM date and time word into six words (year, month, day, hours, minutes and seconds).

Usage

CALL DECODT (NDT, IYR, IMO, IDY, IHR, IMI, SEC)

\section{Parameters}

NDT Internal PODM representation of the date and time to be decoded (a two word array). 
IYR Year

IMO Month of year

IDY Day of month

INR Hours on a 24-hour clock

IMI Minutes

SEC Seconds to 0.1 seconds (floating point word)

(IYR, IMO, IDY, IHR, IMI and SEC are the parameters computed by DECODT)

\section{D.2.4 Function KUNITS}

\section{Function}

KUNITS is used to extract the code for the engineering units of a sensor from the fourth word of a retrieved sensor record. The units codes are defined in Appendix A.

Usage

KEU = KUNITS (MREC(4))

\section{Parameters}

KEU Engineering units code.

MREC Array containing a sensor record returned by GETMSO. The engineering units code is embedded in the fourth word of this array.

\section{D.2.5 Function ICOND}

\section{Function}

ICOND returns the status of a sensor record. 
Usage

ST $=$ ICOND(MREC (4))

\section{Parameters}

ST Status of sensor record (a character*1 variable). ICOND returns one alphanumeric character. The possible status characters and their meanings are:

$$
\text { '*' = invalid signal }
$$

' $H$ ' = high alarm limit exceeded.

' $L$ ' = sensor value is under the low alarm limit

' $N$ ' = increased scan rate

, = status normal

MREC Array containing a sensor record. The status bits are embedded in the fourth word of the record.

\section{D.2.6 Function ISTATWD}

\section{Function}

ISTATWD returns an integer word containing the 16 status bits.

Usage

$I S T=I S T A T W D(M R E C(4))$

\section{Parameters}

IST an integer word containing the 16 status bits right justified.

MREC Array containing a sensor record. The status bits are embedded in the fourth word of this array.

\section{D.2.7 Subroutine SENREC}

\section{Function}

SENREC returns a sensor value, units code and status word given a coded sensor record. 
Usage

Cal1 SENREC (MREC(3), VAL, IUN, ISTT)

\section{Parameters}

VAL Sensor value in engineering units (a 32-bit IEEE floating point word)

IUN Engineering units code

IST 16 status bits right justified

MREC Array containing a coded sensor record. The sensor value in the third word of this array, and the units code and status bits are embedded in the fourth word.

\subsubsection{Function IVALIO}

\section{Function}

IVALID determines from a 16-bit sensor status word whether a sensor record is valid or not.

\section{Usage}

$L=$ IVALID (IST)

\section{Parameter}

IST An integer word containing the 16 status bits right justified, as obtained using ISTATWD (D.2.6) or SENREC (D.2.7).

$\mathrm{L} \quad$ Set to 1 if the status bits indicate an invalid signal, and 0 otherwise. 


\section{D.2.9 Subroutine NEXTIM}

\section{Eunction}

NEXTIM adds a time increment to an internal PODM formatted date and time word to yield another internal PODM formatted date and time (Table D-1).

\section{Usage}

CALL NEXTIM(NDT, IH, IM, DS, LDT)

\section{Parameters}

NOT Two element base date and time in internal PODM format.

IH Time increment, nonnegative integer hours.

IM Time increment, nonnegative integer minutes.

DS Time increment, nonnegative floating point seconds.

LDT Array containing the result of adding IH hours, IM minutes and DS seconds to date and time NDT. LDT is in internal PODM format.

\section{D.2.10 Subroutine IPAST}

\section{Furction}

IPAST subtracts a time increment from an internal PODM formatted date and time to yield another internal PODM formatted date and time.

Usage

CALL IPAST(NDT, IH, IM, DS, LDT)

\section{Parameters}

NDT Two element array containing the base date and time in internal PODM format. 
IH Time increment, nonnegative integer hours.

IM Time increment, nonnegative integer minutes.

DS Time increment, nonnegative floating point seconds.

LDT Result of subtracting IH hours, IM minutes, and DS seconds from NDT. LDT is in internal PODM format.

\section{D.2.11 Subroutine CLEAR and CLEARC}

\section{Eunction}

CLEAR is used to initialize a numeric array to one specified value. CLEARC is used to initialize a character array to one specified character string.

Usage

$\operatorname{CALL} \operatorname{CLEAR}(X, Y, N)$

$\operatorname{CALL} \operatorname{CLEARC}(X, Y, N)$

\section{Parameters}

$Y$ The array to be initialized.

$N$ The length of array $Y$.

$X$ A constant to which array $Y$ is to be initialized.

\section{D.2.12 Function KRONO}

\section{Function}

KRONO determines the chronological ordering of two internal PODM formatted date and time arrays.

Usage

$K=$ KRONO $(T 1, T 2)$ 


\section{Parameters}

T1,T2 Two element arrays each containing an internal PODM formatted date and time.

$K$ If $T 1$ is chronologically after $T 2, K$ is set to 1 . If $T 1$ is chronologically before $T 2, K$ is set to -1 . If $T 1=T 2, K$ is set to 0 .

\section{D.2.13 Function TDIF}

\section{Eunction}

TDIF computes the difference (in seconds) between thio given times. The result is real.

\section{Usage}

$S$ = TDIF(LDATE, TIMEL, IDATE, TIMEI)

\section{Parameters}

LDATE Ending date expressed as a six-digit integer YYMMDD where $Y Y$ is the year, MM is the month and $D D$ is the day. LDATE $=D D+100 * M M+10000 * Y Y$.

TIMEL Ending time expressed as a floating point (real) number. TIMEL $=S+100 * M+10000 * H$ where $S$ is the number of seconds, $M$ is the minutes and $H$ is the hour on a 24-hour clock.

IDATE starting date in same form as LDATE.

TIMEI Starting time in same format as TIMEL.

If the specified ending date and time is earlier than the starting date and time, the result will be negative. 


\section{D.2.14 Subroutine VERSN}

\section{Function}

VERSN returns the version number and release date of the PODMLIB library.

Usage

CALL VERSN(VSN, RELS)

Parameters

VSN The version number (a 6 character variable).

RELS The release date (an 8 character variable). 
Table D-1

Internal PODM Representation of a Date

\begin{tabular}{|c|c|}
\hline Bits & Content \\
\hline $1-17$ & 0 (not used) \\
\hline $18-23$ & $\begin{array}{l}\text { The year biased by } 1976 \text { (i.e., add } 1976 \text { to this value of } \\
\text { these bits to get the actual year) }\end{array}$ \\
\hline $24-27$ & The month $(1-12)$ \\
\hline $28-32$ & The day of the month $(1-31)$ \\
\hline
\end{tabular}

Table D-2

Content of Fourth Word of Data Record Returned by GETMSO

\begin{tabular}{|c|c|}
\hline Bits & Content \\
\hline $1-2$ & Not used \\
\hline $3-9$ & Units code (see Table A-1) \\
\hline $10-20$ & $\begin{array}{l}11 \text { most significant status bits in Table A-2 (bits } 12-16 \\
\text { are not used, so are not stored). }\end{array}$ \\
\hline $21-32$ & $\begin{array}{l}\text { Sensor number (an integer converted from ASCII by PODMLIB } \\
\text { subroutine CA2SN. }\end{array}$ \\
\hline
\end{tabular}

* Bit no. 1 is the leftmost bit in the 32 bit word. 


\section{APPENDIX E}

\section{Sample REQFL/CDREV Run in the Batch Mode}

Table E-1 contains a listing of a runstream for a typical CDREV case. This runstream can be used as a guide in setting up other cases. Changes that users need to make for their own runs are described below.

\section{Lines 1 and 6}

- The runstream in Table E-1 directs all output to a file cdrev.pr. Users may want to specify a different file, or no file.

\section{Line 2}

- Enter a valid access code. "MK" is only an example.

Line 3

- Enter the sensor identification numbers required and/or numbers of groups containing required sensors; terminate list with $\$$. (See REQFL input instruction in Appendix C.1)

\section{Line 4}

- Enter starting and ending date and time for your report. Or, enter CURRENTS if only the latest data are required. (See REQFL input instructions in Appendix C.1.)

\section{Line 5}

- No changes necessary.

Card 6

- Changes described above.

\section{Card 7}

- No changes necessary if output (cdrev.pr) is routed to a device having at least 128 character/line capability. 


\section{Line 8}

- Enter starting and ending date and time for your report. (See input instructions for CDREV in Appendix C.2.)

\section{Line 9}

- Enter the time interval between lines in the report. In the sample case, one hour is specified. (See input instructions for CDREV in Appendix (.2.)

\section{Line 10}

- Enter sensor identification numbers required. Terminate list with $\$$.

\section{Line 11}

- No change necessary.

Table E-1

Sample CDREV Runsteam

1. /apps/sh/reqf1 > cdrev.pr <<EOI

2. MK

3. $1,2 \$$

4. 0318920000,0319922359

5. EOI

6. /apps/sh/xqt cdrev > cdrev.pr <<EOI

7. 10

8. 0318920000,0319922359

9. 10000.0

10. C00000, 21047, 21011A, 21011B, 21014, 21003A, 21042, 21001A\$

11. EOI 


\section{APPENDIX F}

\section{IVHM Parameters Stored in the Data Base}

Sensor Identifier

IVHMGE

IVHMGF

IVHMSN

IVHMOC

IVHMSQ

IVHMCP

\section{Description}

Grapple elevation in inches

Grapple force in pounds

Subassembly serial number (Serial numbers are generally not available on most drives and therefore are frequently zero in the data base)

Operation code used by IVHM to identity the type of drive:

$$
\begin{aligned}
+400 & =\text { UUR (up unloaded restricted) } \\
-400 & =\text { DUR (down unloaded restricted) } \\
+500 & =\text { UUN (up unloaded) } \\
-500 & =\text { DUN (down unloaded) } \\
+600 & =\text { ULS (up loaded storage) } \\
-600 & =\text { DLS (down loaded storage) } \\
+700 & =\text { ULC (up loaded core) } \\
-700 & =\text { DLC (down loaded core) }
\end{aligned}
$$

\begin{tabular}{|c|c|c|c|c|c|}
\hline $\begin{array}{l}\text { Cel1 } \\
\text { or Port }\end{array}$ & $\begin{array}{l}\text { Data Base } \\
\text { Identifier }\end{array}$ & $\begin{array}{l}\text { Cel1 } \\
\text { or Port }\end{array}$ & $\begin{array}{l}\text { Data Base } \\
\text { Identifier }\end{array}$ & $\begin{array}{l}\text { Cell } \\
\text { or Port } \\
\end{array}$ & $\begin{array}{l}\text { Data Base } \\
\text { Identifier } \\
\end{array}$ \\
\hline$X A$ & $\times 001$ & $x H$ & $x 008$ & $x U$ & $x 015$ \\
\hline$X B$ & $\times 002$ & $x J$ & $\times 009$ & $x V$ & $x 016$ \\
\hline$x C$ & $x>03$ & $x K$ & $x 010$ & $x W$ & $\times 017$ \\
\hline$X D$ & $\times 004$ & $x L$ & $\times 011$ & $x X$ & $x 018$ \\
\hline$X E$ & $\times 005$ & $X M$ & $x 012$ & $x Y$ & $\times 019$ \\
\hline$x \bar{F}$ & $x 006$ & $x R$ & $x 013$ & xFTP & $x 020$ \\
\hline$X G$ & $\times 007$ & $x S$ & $\times 014$ & XCRP & x021 \\
\hline
\end{tabular}

IVHM move sequence number

Four digit number indicating the core lattice position, IVS cell or transport that the grapple is over. For core positions, the normal four-digit identifiers are used. However, for other cells and ports, special four-digit codes were created. These codes are listed below.

where, $x$ is the trisector number $(1,2$ or 3$)$, $X A$ through $X Y$ are in-vessel storage (IVS) cells, FTP = fuel transport port, $C R P=$ core restraint pin. 

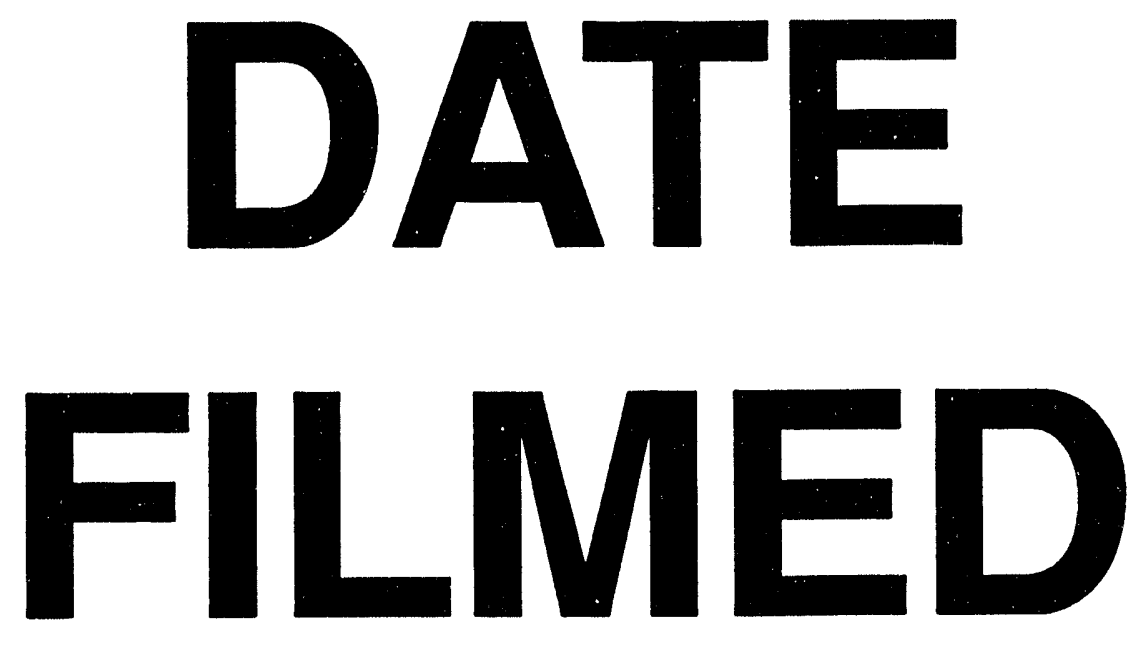

$10 / 5 / 94$
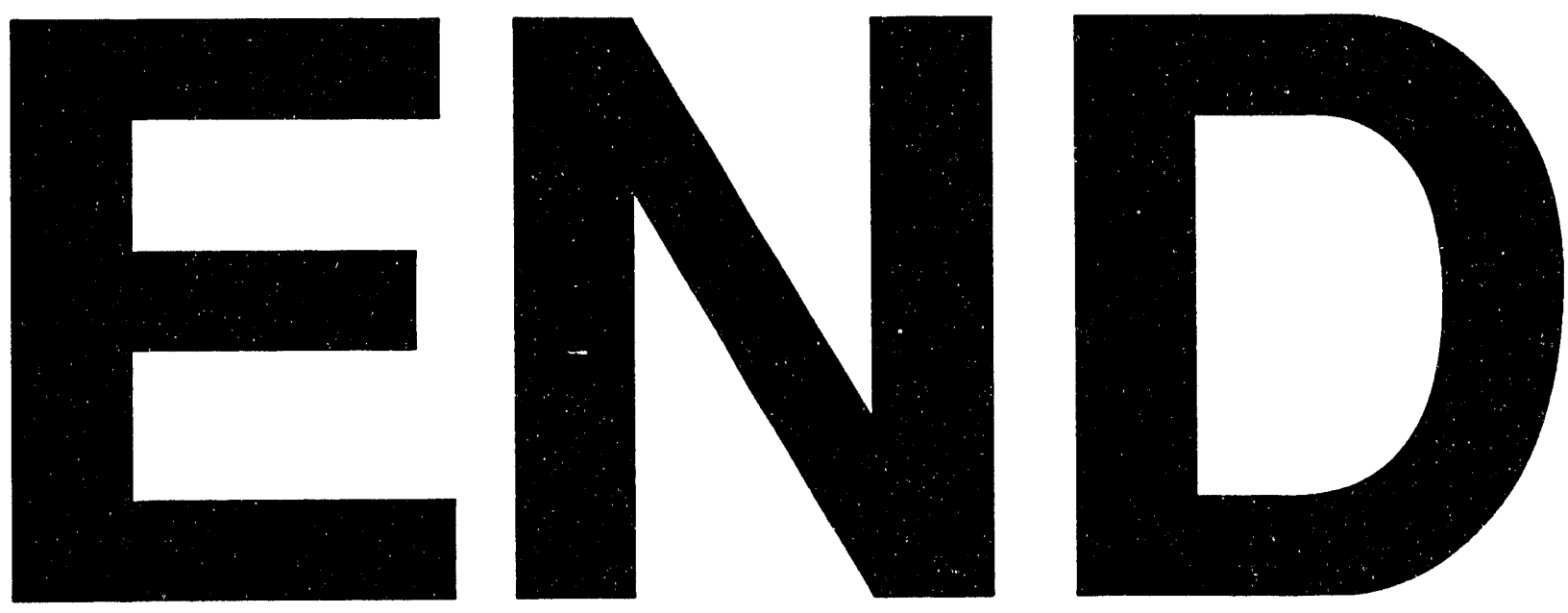


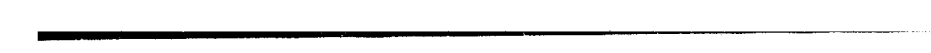

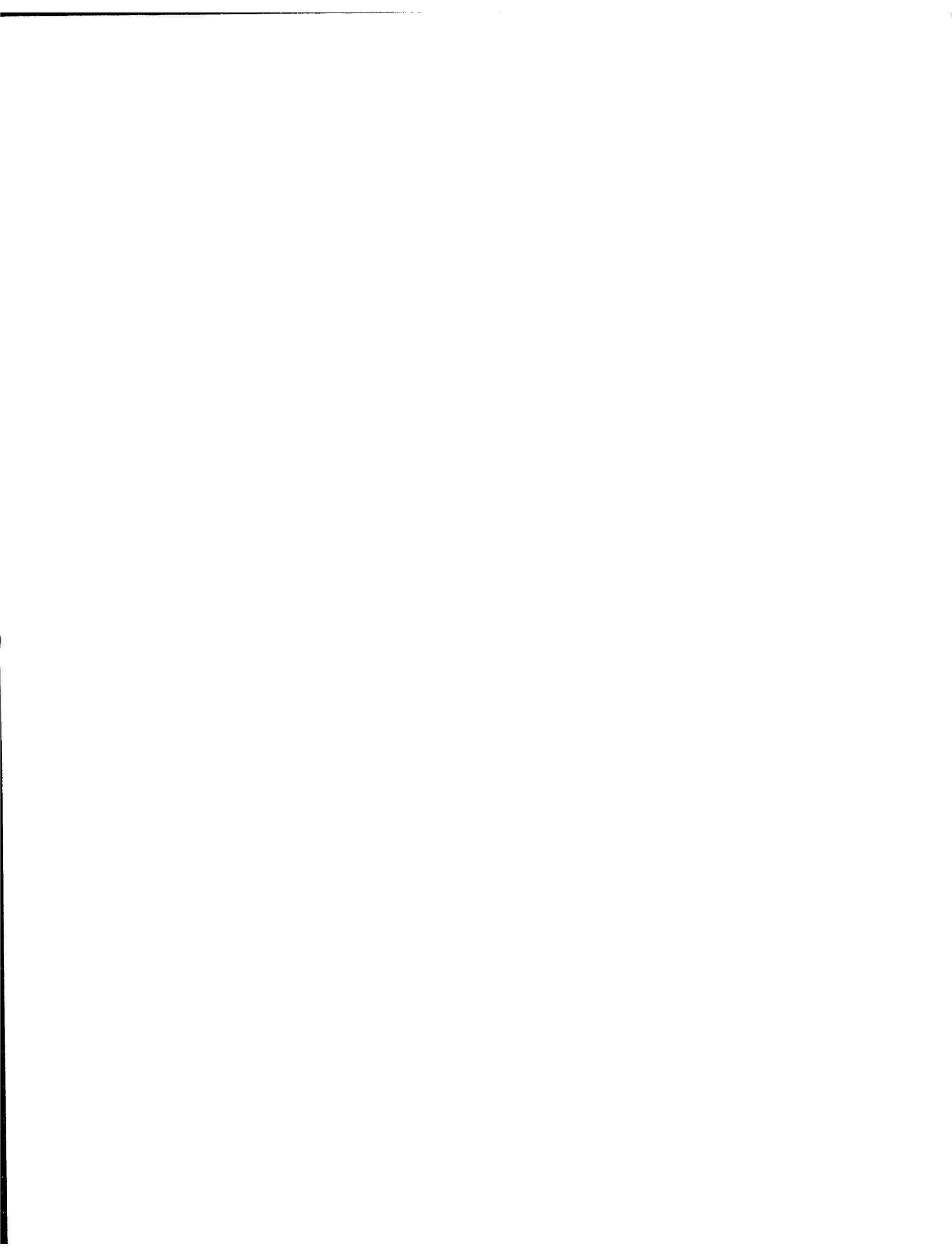

